\title{
Proyectos de Investigación
}

\author{
Formativa \\ Memorias de investigación \\ 2005-2010 \\ UNIMETA
}

Ruber Hernán García Franco

Jorge Ernesto Cárdenas

\section{ESCUELA DE CIENCIAS ADMINISTRATIVAS PROGRAMA DE ADMINISTRACIÓN DE EMPRESAS}

AÑO 2005

\section{ESTUDIO DE FACTIBILIDAD DE UNA COMERCIALIZADORA DE PLÁTANO PRECOCIDO EN VILLAVICENCIO}

\section{Codigo en Biblioteca UNIMETA}

$382 \mathrm{~N} 46 \mathrm{e}$

\section{AUTORES}

Arias Hernández Gina Carolina

Niño Bustos María Carolina

\section{RESUMEN}

El presente estudio de factibilidad de una comercializadora internacional de alimentos de plátano precocido en Villavicencio, refleja que en el departamento del Meta sí se pueden emprender medianas empresas, y que los diferentes sectores agroindustriales y poblaciones cercanas a la ciudad, tienen y tendrán necesidades que pueden ser satisfechas por esta economía de escala dada por una industria regional.

Teniendo en cuenta este diagnóstico se puede definir que el departamento del Meta es una región con una producción actual de plátano que abastece el mercado regional, con suficientes excedentes que servirán para procesos industriales, porque los productos de plátano consumidos en la región son traídos del interior del país. Partimos de esta base hacia la investigación y realización del trabajo de tesis sobre el estudio de factibilidad de un proyecto encaminado a la comercialización internacional del plátano del Ariari, área perteneciente a nuestro departamento del Meta.

\section{OBJETIVO GENERAL}

Determinar a partir de la producción de plátano en el departamento del Meta la factibilidad para el montaje de una comercializadora de plátano precocido en Villavicencio, que permita exportar hacia los Estados Unidos (Miami) y con visión global.

\section{OBJETIVOS ESPECÍFICOS}

- Conocer y analizar la producción de plátano en la zona del Ariari.

- Realizar un análisis de la aceptación del producto con base en datos históricos de exportación de plátano precocido y congelado desde el año 1999 al 2002 desde Colombia a la ciudad de Miami.

- Diseñar y establecer el estudio técnico que requiere el proyecto.

- Determinar la estructura administrativa en la comercialización internacional.

- Realizar el análisis financiero y económico para determinar la factibilidad del proyecto.

\section{JUSTIFICACIÓN}

El proceso de globalización trae grandes beneficios a las naciones que, en el caso de Colombia, dadas sus especiales 


\section{ISSN-2248-736 * Número 3 * Revista Facta Non Verba}

condiciones de carácter político y social, tendrán un mayor impacto sobre la población y los indicadores sociales, además de la estructura productiva y la economía del país. Es determinante que se tome conciencia del proceso de mundialización y su irreversible avance, por lo que todas las instancias productivas deben asumirlo y enfrentarlo con la mejor preparación, motivo por el cual el gobierno debe poner a su disposición las herramientas para lograrlo.

La presente investigación, desea demostrar que es posible desarrollar una inversión, con un alto nivel de ingresos dirigida a mejorar la capacidad económica de los inversionistas y de los proveedores, que redunde en el desarrollo económico del país.

\section{CREACIÓN DE UNA MICROEMPRESA PRESTADORA DE SERVICIOS INTEGRALES PARA LA ORGANIZACIÓN DE MATRIMONIOS EN LA CIUDAD DE VILLAVICENCIO}

\section{Codigo en Biblioteca UNIMETA}

306.81 L18c

\section{AUTORES}

Lasprilla Gustavo Alberto

\section{RESUMEN}

Unirse en matrimonio con la persona que se ama es el anhelo de una pareja, por esto el evento tiene un especial significado, y amerita una gran celebración.

La visión de la empresa es la organización integral de matrimonios, los cuales deben estar al alcance del presupuesto de los clientes y ofrecer la mayor calidad posible.

La empresa ofrecerá los servicios de: tarjetas de invitación, salón de recepciones, dotación, decoración, cena, bebidas, licores, elaboración de ponqués, transporte, fotografía, filmación, musical y planes para la luna de miel.

En el estudio de mercado se describen los clientes potenciales que se segmentaron en cuatro grupos, de estos se decide desarrollar el estudio técnico, y financiero enfocado para clientes de perfil tipo 3. Clientes que invierten entre $\$ 3.000 .000$ y $\$ 8.000 .000$ para la fiesta, utilizan servicios sencillos, bonitos más no muy elegantes. Corresponde al 43,5\% de los habitantes.

El estudio arroja que el montaje de este proyecto, sin ninguna financiación, arroja una tasa interna de retorno del $17 \%$ y con financiación una tasa del 29\%.

\section{OBJETIVO GENERAL}

Ofrecer un servicio integral y versátil de organización de matrimonios, que permita al cliente adquirir un portafolio completo de servicios necesarios para la organización del evento, acorde con el poder adquisitivo del cliente.

\section{OBJETIVOS ESPECÍFICOS}

- Mediante el estudio de mercado describir los clientes potenciales, el cliente objetivo y la competencia.

- Realizar un estudio técnico que contribuya a mostrar las características de ingeniera del proyecto y composición administrativa que permitan prestar un servicio de buena calidad, acorde a las necesidades del cliente objetivo, y ofrecer una mejor alternativa que la competencia. - Desarrollar el estudio económico y la evaluación financiera que permitan dilucidar la viabilidad económica del proyecto para tomar la decisión de inversión.

\section{JUSTIFICACIÓN}

Diseñar empresas y productos específicos para diferentes segmentos de clientes es una necesidad para que las empresas modernas puedan competir en el mercado. Al mismo tiempo, en el mercado se presentan infinitas oportunidades de negocios, como diferentes son las personas en sus gustos, necesidades y poder adquisitivo.

La alternativa de ofrecer un servicio de organización de eventos matrimoniales, donde el cliente encuentre en la empresa la gran mayoría de los servicios involucrados en la organización del evento, al mismo tiempo que se va a encontrar un servicio diseñado acorde con sus necesidades, gustos y posibilidades económicas, será una gran fortaleza que permitirá a la empresa posicionarse rápidamente en el mercado.

Es fundamental cuando se pretende crear una nueva empresa establecer las diferencias de los posibles clientes. Las diferencias existentes dan la pauta para poder diseñar una empresa que se acerque a las necesidades, gustos y posibilidades económicas del que será el "cliente objetivo". 
Este cliente objetivo se halla a partir de la descripción de una gama de clientes potenciales, de entre los cuales la empresa determinará quién o quienes constituirán los "clientes objetivo".

Se pretende prestar un servicio al cliente, acorde con lo que él quiere, y pueda costear según su presupuesto, necesidades y preferencias. A través de la descripción del comportamiento de consumo y los diferentes segmentos de clientes, se podrá decidir cuál será el perfil del cliente objetivo. Al conocer sus características de consumo y su poder de compra, se podrá diseñar una empresa que ofrezca productos y servicios acordes con la necesidad del cliente.

\section{ANÁLISIS DE LA CADENA PRODUCTIVA DEL PLÁTANO EN EL DEPARTAMENTO DEL META Y SU PERSPECTIVA DEL DESARROLLO}

Codigo en Biblioteca UNIMETA

634.773 M26A

\section{AUTORES}

Willington Mendoza Espitia

José Julián Poveda

\section{RESUMEN}

Este proyecto se presenta como una alternativa de solución a problemas presentados en el sector platanero, denotándose las altas pérdidas post-cosechas del plátano producidas en el departamento del Meta, debido a la falta de óptimas vías de comunicación, deficiencias en las técnicas de conservación, el transporte, la producción dispersa, y la ausencia de la integración entre el productor, el transformador y el comercializador.

\section{OBJETIVO GENERAL}

Determinar la situación actual de la cadena productiva del plátano en el departamento del Meta con el fin de recomendar lineamientos que contribuyan al desarrollo de la región.

\section{OBJETIVOS ESPECÍFICOS}

- Acopiar la información existente entre la relacionada con el tema a nivel internacional, nacional y regional.

- Identificar la conformación de los eslabones que constituyen la cadena productiva del plátano.

- Identificar las debilidades y fortalezas a lo largo de la conformación de la cadena productiva.

- Dar los lineamientos más convenientes para la conformación óptima de la cadena productiva del plátano.

\section{JUSTIFICACIÓN}

La cadena nacional del plátano ha descrito la dedicación de las grandes zonas productoras en el país de acuerdo a su posición geográfica, así:

La zona costera especialmente el Urabá, suministra productos al mercado internacional; la zona del eje cafetero, en la que el centro de comercio está en Armenia, suministra productos para la industria, y la zona de los llanos orientales cuya principal función consiste en suministrar productos al principal consumidor que es la capital del país. En éste sector el país se mejorado tecnológicamente lo cual ha llevado al incremento de la productividad.

\section{PROPUESTA DE LA IMPLEMENTACIÓN DE LA NORMA ISO 9001 EN LA EMPRESA DE TRANSPORTES ARIMENA S.A VILLAVICENCIO}

Codigo en Biblioteca UNIMETA

$58.562 \mathrm{~B} 71 \mathrm{P}$

\section{AUTOR}

Diana Paola Bray Saavedra

\section{RESUMEN}

Para la implementación de un sistema de gestión de calidad todo el personal de la empresa debe estar comprometido a realizar cambios en la forma como lleva a cabo las labores diarias; es decir, todos los procesos de la alta dirección hasta los operarios, deben poseer la competencia y la experiencia que les permita desempeñarse mejor en un sitio de trabajo con sentido de pertenencia y estar más comprometidos. 
ISSN-2248-736 * Número 3 * Revista Facta Non Verba

para lograr posesionar la empresa como la número uno en el mercado de transporte, pasajeros y carga OBJETIVO GENERAL

Proponer a las directivas de la empresa transportes ARIMENA S.A. la implementación la norma de gestión de calidad ISO 9001 VERSION 2000.

\section{OBJETIVOS ESPECÍFICOS}

- Conocer el funcionamiento de la empresa TRANSPORTES ARIMENA S.A

- Aplicar el DOFA en el manejo de la empresa de transportes ARIMENA S.A en el área administrativa.

- Sugerir sistemas de comunicación interna dentro de la organización para obtener un eficaz sistema de la calidad.

- Dar a conocer a la empresa ARIMENA S.A los beneficios que ofrece el incrementar la norma ISO 9001.

\section{JUSTIFICACIÓN}

Cualquier actividad o conjunto de actividades que utiliza recursos para transformar elementos de entrada en resultados, puede considerarse como un proceso para que las organizaciones operen de manera eficaz, tiene que identificar y gestionar numerosos procesos interrelacionados y que interactúan.

A menudo el resultado de un proceso se constituye directamente como el elemento de entrada a un proceso. Es por eso que se hace necesaria la implementación de un sistema de calidad en la empresa transportes ARIMENA S.A. para mejora en sus procesos y en la calidad del servicio, contando siempre con los soportes necesarios y la identificación de funciones de cada uno de los colaboradores que operan dentro de la organización.

\section{ANÁLISIS SITUACIONAL DEL SECTOR TURÍSTICO EN EL MUNICIPIO DE PUERTO LÓPEZ - META}

Codigo en Biblioteca UNIMETA

338.479 CH15a

AUTORES

Lina Jalime Chálela Álvarez

Lindelia Javela Rojas

\section{RESUMEN}

El turismo se ha convertido en una de las actividades más importantes del mundo, y los ingresos generados por el mismo suponen ya una parte importante en la economía mundial. El departamento del Meta posee una amplia oferta natural soportada en paisajes, llanuras, amaneceres, lagunas, cascadas, cachiveras, esteros, morichales, garceros, bosques de conglomerado de una oferta un tanto dispersa que requiere una integración de componentes para conformar un producto turístico que identifique a la región y la posesione en el contexto nacional como destino turístico por excelencia.

\section{OBJETIVO GENERAL}

Analizar la situación actual del sector turístico del municipio de Puerto López e identificar estrategias que permitan posicionar al municipio en el mundo globalizado de hoy, como sitio por excelencia en el departamento del Meta.

\section{OBJETIVOS ESPECÍFICOS}

- Realizar el análisis situacional del sector turístico del municipio de Puerto López (Meta).

- Establecer cada uno de los principales recursos y sitios turísticos de municipio de Puerto López (Meta).

- Identificar en el municipio de Puerto López las estrategias y proyectos que permitirán su desarrollo turístico.

- Diseñar estrategias que permitan desarrollar los proyectos propuestos para incentivar el sector turístico del municipio de Puerto López

\section{JUSTIFICACIÓN}

La situación económica actual por la que atraviesa Colombia ha hecho, que tanto el gobierno nacional como el departamental, hayan visto la necesidad de diseñar planes y programas de promoción turística que permitan impulsar este reglón de la economía, aprovechando así los recursos naturales que posee el país.

\section{VIABILIDAD DE UN CENTRO DE ACOPIO EN EL MANEJO DE POSTCOSECHA DE CÍTRICOS EN VILLAVICENCIO.}

\section{$634.3 \mathrm{C} 18 \mathrm{~V}$}

\section{AUTORES}

Yuli Alejandra Castillo Gaitán

Oscar Armando Gutiérrez Rodríguez

\section{RESUMEN}

Colombia presenta una dinámica importante en la 
producción de cítricos, especialmente en lo que se refiere a las naranjas, mandarinas y lima-limón. Además, al considerar la producción de cítricos en Colombia vemos que se presenta una gran dispersión en la medida en que 22 departamentos los producen. De esta característica participa aproximadamente el 31\% del área sembrada con cultivos permanentes y el $1.1 \%$ del área total sembrada en el país.

\section{OBJETIVO GENERAL}

Determinar la viabilidad de un centro de acopio de cítricos en la ciudad de Villavicencio que contribuya a mejorar la comercialización y la competitividad de la citricultura en la región.

\section{OBJETIVOS ESPECÍFICOS}

- Realizar un estudio de mercados a través de la aplicación de una encuesta a productores, mayoristas y consumidores para determinar la oferta y la demanda de los otros cítricos en Villavicencio.

- Diseñar el estudio técnico para determinar el tamaño y localización de la planta, la capacidad, la calidad y cantidad de equipo y demás aspectos pertinentes para el establecimiento del centro de acopio.

- Plantear el estudio administrativo para un centro de acopio en la ciudad de Villavicencio.

\section{JUSTIFICACIÓN}

La mayoría de los cultivos actuales de cítricos no están tecnificados y son de calidad media con lo cual no se garantiza un volumen constante de producción y una alta calidad como lo exigen los mercados.

\section{PERSPECTIVA DEL CONSUMO DE AROMÁTICAS DE FRUTAS EN LOS HABITANTES DE VILLAVICENCIO (META)}

\section{Codigo en Biblioteca UNIMETA}

634 B67p

\section{AUTORES}

Nilsa Rocío Borda Torres.

Diana Carolina Rodríguez Páramo.

\section{RESUMEN}

En la década de los noventa inicia un proceso de consolidación de la organización gremial de productos de frutas y hortalizas (Asohofrucol). Aunque el país no cuenta con un completo sistema de información del sector frutícola de Colombia, Asohofrucol calcula que se cuenta con un área plantada en frutas y hortalizas de 145.000 hectáreas, repartidas en 72 especies diferentes, las cuales son utilizadas para el consumo en fresco y algunas para el procesamiento.

Es un hecho que en Colombia el desarrollo de la agroindustria es incipiente, por lo tanto, hacia el futuro se hace necesario pensar con criterio de gran empresa en la promoción y modernización de la industria alimentaria a partir de frutas y hortalizas, con un esquema que incorpore cadenas productivas, desarrollo rural y gestión empresarial.

\section{OBJETIVO GENERAL}

Analizar las perspectivas del consumo de aromáticas de frutas en los habitantes de Villavicencio.

\section{OBJETIVOS ESPECÍFICOS}

- Recolectar la información existente sobre las aromáticas de frutas en cuanto a su parte técnica.

- Establecer las bondades del consumo de las aromáticas de frutas como complemento de la fruto terapia para incentivar su consumo.

- Identificar las empresas que producen las aromáticas de frutas y sus principales canales de distribución.

- Identificar las áreas cultivadas de cítricos en el departamento del Meta como materia prima para la elaboración de las aromáticas de frutas.

- Conocer los habitantes y la necesidad de los consumidores de bebidas aromáticas de la ciudad de Villavicencio a través de la aplicación de encuestas.

\section{JUSTIFICACIÓN}

El departamento del Meta cuenta con recursos naturales aptos para el manejo de cultivos de productos frutícolas de muy buena calidad, sin embargo, se hace necesario implementar nuevas tecnologías que permita tanto a los agricultores como a los industriales aprovechar la producción para lograr ofrecer nuevas alternativas al consumidor final.

VIIIIIIIIIIIIIIIIIIIIIIIIIIIIII

Facta Non Verba

Revista 


\section{DIAGNÓSTICO DE LA CAPACIDAD INSTALADA EN LA AGROINDUSTRIA ARROCERA EN EL DEPARTAMENTO DEL META}

Codigo en Biblioteca UNIMETA

$338.1 \mathrm{M} 17 \mathrm{~d}$

\section{AUTORES}

Luis Adán Martínez Rocha

Eider Reina Espinosa

\section{RESUMEN}

El país cuenta con una industria que posee todos los niveles tecnológicos. Colombia tiene hoy en operación cerca de 100 molinos, de los cuales se estima que un $30 \%$ de ellos operan temporalmente, sin suficiencia operativa y económica y responde exclusivamente a la estacionalidad de la cosecha. Según el censo realizado por FEDEARROZ en 1989 operaban cerca de 400 molinos en el país. Es válido aclarar que esta estadística incluía plantas del IDEMA que no realizaban sino labor de secamiento. Lo importante para destacar es que por lo menos 200 molinos han cerrado sus puertas.

\section{OBJETIVO GENERAL}

Realizar un diagnóstico de la capacidad instalada en la agroindustria arrocera en el departamento del Meta.

\section{OBJETIVOS ESPECÍFICOS}

- Determinar la capacidad instalada en agroindustria arrocera y el porcentaje de utilización actual.

- Identificar el volumen manejado en producto principal y productos secundarios que se obtiene de la industria arrocera.

- Identificar la esencia de la materia prima.

\section{JUSTIFICACIÓN}

Se hace necesario realizar un diagnóstico de la agroindustria arrocera en el departamento del Meta y de su perspectiva de desarrollo, teniendo en cuenta el incremento de las áreas cultivadas en el departamento del Casanare durante los últimos dos años, y el hecho de que este departamento no cuente con una infraestructura instalada para la transformación del arroz paddy.

\section{IDENTIFICACIÓN DE UNA ALTERNATIVA A TRAVÉS DEL CULTIVO DE CAUCHO EN EL DEPARTAMENTO DEL META}

Codigo en Biblioteca UNIMETA 338 G88I

\section{AUTORES}

Jorge Gutiérrez Hernández Humberto Pinilla Pinilla.

\section{RESUMEN}

El caucho es un hidrocarburo, cuya materia prima es el látex producida a través del sangrado de la corteza de varias moráceas y euforbiáceas intertropicales entre las que se destacan las Hebea brasiliensis, especie arbórea autóctona de la cuenca del Amazonas. El cultivo del caucho y la producción de látex tienen un escaso desarrollo. Se ha pensado en las potencialidades agroecológicas y socioeconómicas de éste cultivo en el marco del eslabonamiento con otros actores industriales de esta importante actividad.

\section{OBJETIVO GENERAL}

Diagnosticar una alternativa de producción a través del cultivo de caucho en el departamento del Meta.

\section{OBJETIVOS ESPECÍFICOS}

- Identificar las plantaciones existentes en el departamento del Meta

- Determinar costos de producción por hectárea.

- Determinar el proceso de recolección del LÁTEX y la obtención de subproducto.

- Identificar los canales de comercialización de los subproductos de caucho.

\section{JUSTIFICACIÓN}

La Orinoquia es considerada como la mejor zona de escape al mal suramericano de las hojas, enfermedad limitante en el cultivo de caucho natural, encontrándose cerca de 200.000 hectáreas aptas para su cultivo. Hoy contamos en el departamento del Meta con unas 725 hectáreas de caucho.

La empresa Mavalle Ltda. Constituye un polo de desarrollo heveícola en el departamento del Meta, con su cultivo comercial y planta transformadora de caucho. En estas condiciones, el Meta puede ser el primer productor de caucho del país, lo que le permite generar el empleo y la condición de vida de los productores, además de la productividad agrícola del departamento. 


\section{AÑO 2008}

\section{PLAN DE CAPACITACIÓN PARA MEJORAR EL CLIMA LABORAL EN CORPOICA VILLAVICENCIO}

Codigo en Biblioteca UNIMETA

358.3124 A12P

\section{AUTORES}

Abel Jamid Abdala González

María Carolina Niño Azula

\section{RESUMEN}

Un recorrido por destacadas obras de especialistas de la administración de recursos humanos muestra claramente la importancia que ha ido adquiriendo el tema de la cultura y el clima laboral para proporcionar un conocimiento más completo con respecto al fenómeno administrativo. Esto representa un avance en el enfoque que pretenda conocer y explicar dicho fenómeno a través del análisis de la conducta de los miembros de la organización y de las relaciones personales que necesariamente en ella se establece.

\section{OBJETIVO GENERAL}

Proponer un plan de capacitación al personal de CORPOICA, que mejore el clima laboral.

\section{OBJETIVOS ESPECÍFICOS}

- Conocer las percepciones y motivaciones del individuo frente a su trabajo.

- Determinar el grado de satisfacción de los empleados y su incidencia en el clima laboral.

- Elaborar un diagnóstico sobre el clima laboral que vive actualmente en CORPOICA.

- Implementar políticas y prácticas adecuadas del recurso humano, las cuales redundaran en una mejora de la eficiencia y eficacia de la organización y un mejor manejo de los recursos humanos.

- Diseñar el plan de intervención.

\section{JUSTIFICACIÓN}

El buen funcionamiento de una organización, depende en gran porcentaje del ánimo o actitud de los trabajadores de la misma, que se enfoquen hacia sus tareas, claro está, que algunas veces nos encontraremos con empleados que se dediquen única y exclusivamente a terminar a como dé lugar sus tareas, sin preocuparse de la calidad de las mismas, afectando de grave manera el desarrollo de la organización.

\section{AÑO 2009}

\section{DISEÑO DE LA AGENCIA DE DESARROLLO LOCAL DE VILLAVICENCIO}

\section{Codigo en Biblioteca UNIMETA \\ T 307.14 C14d}

\section{AUTOR}

\section{Bladimir Caicedo Mogollón}

\section{RESUMEN}

Esta investigación, explora una alternativa de solución a la problemática económica en que vive un alto porcentaje de los villavicenses, de acuerdo con los indicadores de pobreza, indigencia, desarrollo y oportunidades de trabajo. Su objetivo es demostrar que en Villavicencio se requiere implementar modelos de desarrollo que implique el mejoramiento de las agencias de desarrollo local (ADEL).

La presente investigación abre la puerta para el desarrollo de una ADEL en Villavicencio, al formular un plan de acción que permita conocer nuestro verdadero potencial endógeno, estimular la organización de cadenas de valor territorial, y diseñar estrategias que permitan un mayor desarrollo estructural y económico en la localidad.

\section{OBJETIVO GENERAL}

Elaborar el diseño de la Agencia de Desarrollo Local de Villavicencio (ADELV), para el mejoramiento permanente de la calidad de vida de la población y así asegurar la dignidad humana.

\section{OBJETIVOS ESPECÍFICOS}

- Diseñar la fase de promoción de la ADELV.

- Diseñar la fase de constitución de la ADELV.

- Determinar la fase de estructuración y arranque de la ADELV 


\section{ISSN-2248-736 * Número 3 * Revista Facta Non Verba}

- Planificar las fases de consolidación de la ADELV. JUSTIFICACIÓN

La necesidad de encontrar estrategias que permitan construir un desarrollo local, donde existe mayor oportunidad deingresosyobtenerunavidadigna,parala poblacióneconómicamente vulnerable de la ciudad de Villavicencio.

\section{PROGRAMA DE CONTADURÍA PÚBLICA}

\section{AÑO 2005 \\ LA AUDITORIA Y LA VALORACIÓN DEL IMPACTO AMBIENTAL EN LAS ORGANIZACIONES DEL SECTOR INDUSTRIAL EN VILLAVICENCIO}

\section{Codigo en Biblioteca UNIMETA}

$657.45 \mathrm{C} 78 \mathrm{a}$

\section{AUTORES}

Sandra Milena Cruz Piraquive

María Mercedes Lugo Sarta.

\section{RESUMEN}

Los conceptos medio ambiente y desarrollo ambiental sostenible, se han convertido en el paradigma del momento para todas las organizaciones. Por ello se dice que los problemas ambientales que han surgido como consecuencia del daño que el hombre causa al medio ambiente y especialmente a las empresas industriales, son los nuevos problemas de los negocios, y en ellos debe tenerse en cuenta tanto los términos de legislación como los cambios en el concepto de sostenibilidad de mercados; ellos tienen implicaciones directas en el área contable y en los aspecto de los costos de la empresas con repercusión total en todas y en cada una de las decisiones que tomen.

\section{OBJETIVO GENERAL}

Realizar un estudio sobre los elementos que contribuyen a determinar y valorar el impacto ambiental, y presentarlo en los estados financieros de las empresas del sector industrial en Villavicencio.

\section{OBJETIVOS ESPECÍFICOS}

- Establecer el marco teórico, conceptual y legal que soporta la auditoría ambiental en el orden nacional e internacional, como herramienta para la auditoría ambiental

de las empresas industriales en la ciudad de Villavicencio.

- Realizar un diagnóstico del contexto actual de la gestión ambiental y los procesos de auditoría ambiental aplicados en las empresas del sector industrial de la ciudad de Villavicencio

- $\quad$ Establecer herramientas para el desarrollo de la auditoría ambiental dirigida a aquellos profesionales que requiera este tipo de información.

\section{JUSTIFICACIÓN}

Los estados financieros de las empresas hoy, no están teniendo en cuenta los efectos del daño ambiental, ni los costos que acarrea el tránsito a industrias de tecnologías limpias, con los nuevos modelos de negociación, las oportunidades generadas por la globalización y la apertura de fronteras. Quienes pretenden negociar en el exterior y quienes se pretenden sostenerse en el mercado, deberán dar cumplimiento a la legislación ambiental vigente en Colombia y acreditar los procesos en los que se están trabajando según las normas ISO 14000 y 14001.

\section{MANUAL DE PROCEDIMIENTOS PARA LA EJECUCIÓN PRESUPUESTAL Y TESORAL DE LA INSTITUCIÓN EDUCATIVA COLEGIO JUAN PABLO II}

\section{Codigo en Biblioteca UNIMETA}

$658.154 \mathrm{~J} 17 \mathrm{M}$

\section{AUTOR}

\section{Giuseppe Jaramillo Otálora}

\section{RESUMEN}

La institución educativa JUAN PABLO II de Villavicencio es una entidad de carácter oficial, la cual debe suministrar información de índole financiero a los diferentes encargados del control, como son las Contralorías y las Secretarias de Educación, las cuales vigilan el manejo del presupuesto del año lectivo, por ende se hace necesario implementar mecanismos internos en las áreas de presupuesto y tesorería de tal manera que la información generada en el interior de las organizaciones sea eficaz, efectiva y oportuna. 


\section{OBJETIVO GENERAL}

Elaborar el manual de procedimiento para la ejecución presupuestal y tesorera de la institución educativa $\mathrm{CO}$ LEGIO JUAN PABLO II.

\section{OBJETIVOS ESPECÍFICOS}

- Identificar los procedimientos para el manejo presupuestal y tesorero en la institución educativa COLEGIO JUAN PABLO II

- Establecer los puntos de control para cada uno de los procedimientos.

- Elaborar diagramas de flujo para cada uno de los procedimientos que hacen parte del manual.

- Definir procedimientos que hacen parte del manual.

- Definir los procedimientos para la ejecución de los proceso en la institución.

- Documentar y normalizar los procesos y procedimientos en los cuales se fundamenta la institución.

- Adecuar el manual de procedimientos generales en el área de presupuesto y tesorería.

\section{JUSTIFICACIÓN}

En la actualidad las instituciones educativas se encuentran con la obligación de rendir informes en forma periódica a los organismos de control (Contraloría y Secretarias de Educación). Para llevar a cabo la elaboración de estos, se debe tener en cuenta una serie de mecanismos que permitan un nivel tesorero y presupuestal. Por tal motivo, se hace necesario elaborar un manual que dinamice y sirva de guía para la ejecución de las diferentes tareas que desempeña un funcionario que se encuentra nombrado en el cargo de tesorero pagador de una institución educativa oficial, el cual debe planear el buen uso del presupuesto asignado.

\section{ANÁLISIS DE LAS REFORMAS PARA LAS COOPERATIVAS DE TRABAJO ASOCIADO Y EL EFECTO GENERADO EN LAS EMPRESAS COMERCIALES E INDUSTRIALES DE VILLAVICENCIO.}

Codigo en Biblioteca UNIMETA

658.047 N63e

\section{AUTORES}

Claudia Patricia Noguera Meneses

Jhon Jairo Gutiérrez Ríos

\section{RESUMEN}

En este trabajo de grado se objetiva la sistematización de un proceso de investigación y practica que se llevó a cabo, a través de un estudio sobre las reformas de las cooperativas de trabajo asociado y, el efecto generado en los nuevos modelos administrativos para la producción, comercialización y de servicios en las municipios de Villavicencio y Acacias, donde funciona actualmente la mayoría de cooperativas de trabajo, con diferentes sistemas de producción, por la variedad de productos agrícolas, ganaderos e industriales que conforman el sistema económico de dichos municipios y del departamento del Meta.

\section{OBJETIVO GENERAL}

Analizar el efecto generado por la reforma para el trabajo asociado en los nuevos modelos administrativos, de producción y de prestación de servicios en las empresas industriales y comerciales y su influencia en la solución al desempleo y la reactividad de la economía de Villavicencio y Acacias.

\section{OBJETIVOS ESPECÍFICOS}

- Analizar la incorporación del trabajo asociado en los nuevos modelos administrativos para la producción y comercialización prestación de servicio en la región.

- Establecer el efecto de las cooperativas asociadas ante la crisis de desempleo en Villavicencio y las garantías que ofrecen con respecto al aspecto laboral.

- Determinarcómo consideran las empresas privadas y públicas la creación de las cooperativas de trabajo asociado.

\section{JUSTIFICACIÓN}

Es de vital importancia analizar la organización y el funcionamiento de las organizaciones de trabajo asociativo, pues se ha venido observando que estas han tenido gran incidencia en las empresas privadas y en la sociedad debido a los beneficios que ofrecen a los trabajadores y desempleados.

\section{GUÍA PARA EL DESARROLLO DE LA CÁTEDRA DE CONTABILIDAD BANCARIA EN LA UNIVERSIDAD DEL META}

Codigo en Biblioteca UNIMETA

$657.47 \mathrm{~B} 26 \mathrm{~g}$

\section{AUTORES}

Elizabeth Benavides Farfán

José Alfredo Santiago Rojas

\section{RESUMEN}

La actividad bancaria en Colombia comprende uno de los sectores más complejos y dinámicos del país, forma 
ISSN-2248-736 * Número 3 * Revista Facta Non Verba

parte fundamental del proceso económico, integrando las diferentes actividades que ejecutan los sectores primarios en la economía. Su desarrollo ha permitido a lo largo de tiempo dinamizar y soportar las transacciones comerciales del orden nacional e internacional. A pesar de su dinamismo y tal vez por su grado de complejidad no se encuentran disponibles en las bibliotecas textos que enseñen a los estudiantes de Contaduría Pública, la forma práctica como se registran cada una de las operaciones que se realizan.

\section{OBJETIVO GENERAL}

Crear una guía que sirva como herramienta a los estudiantes de Contaduría Pública de la Universidad del Meta, para conocer la historia y la evolución de la banca en Colombia, entender e identificar las operaciones bancarias indicadas en la guía de cátedra y facilitar su aprendizaje en cuanto al registro contable de dichas operaciones, bajo las normas que estipula el gobierno y la superintendencia bancaria.

\section{OBJETIVOS ESPECÍFICOS}

- Dar a conocer la historia y la evolución que ha tenido la banca en nuestro país

- Explicar la estructura y organización del sistema financiero en Colombia.

- Identificar las operaciones que realizan los bancos comerciales de Colombia, contenidas en la guía cátedra de contabilidad bancaria.

- Crear un instrumento didáctico que permita a los estudiantes de la facultad de Contaduría Pública, entender la contabilización que realizan los bancos comerciales de Colombia, contenidas en el programa de contabilidad bancaria en la universidad.

\section{JUSTIFICACIÓN}

Durante nuestro proceso de formación profesional observamos que en las diferentes actividades económicas del país la contabilidad está presente, y en cada una de ellas existen textos que indican al estudiante la forma como se registran contablemente los hechos económicos. Por esto nos proponemos crear una herramienta de consulta en este campo para los estudiantes de la Universidad del Meta.

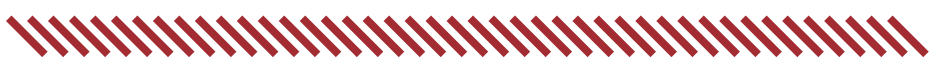

Facta Non Verba

Revista

\section{ANÁLISIS DE LA ASIGNACIÓN DEL GASTO PÚBLICO EN LA COBERTURA DE LA EDUCACIÓN BÁSICA PRIMARIA Y SECUNDARIA EN EL DEPARTAMENTO DEL CASANARE PERIODO 1999-2004}

\author{
Codigo en Biblioteca UNIMETA \\ 370.11 L65e
}

\section{AUTORES}

Cáceres Sánchez Ronel

Lombana Díaz Edwin Fernando

\section{RESUMEN}

La Constitución de 1991 indica que el proceso de descentralización administrativa, no solo busca una mayor eficiencia y equidad, sino que también busca establecer un esquema más efectivo de rendición de cuentas. Lo anterior permite que las acciones realizadas por los gobiernos en sus diferentes niveles puedan ser analizadas por cualquier instancia ciudadana; por lo tanto, este trabajo realzará un análisis exhaustivo al sector de la educación básica primaria y secundaria del departamento del Casanare en la que las variables a considerar van desde determinar los niveles de cobertura alcanzados en cada uno de los años analizados, hasta determinar los crecimientos reales y diferenciar los tipos de ingresos y de gastos utilizados en el sector.

\section{OBJETIVO GENERAL}

Analizar que el presupuesto de la inversión pública destinado al sector educativo, cumpla con las políticas de cobertura educativa establecidas por el gobierno nacional, con el fin de que el gobierno departamental diseñe políticas en cuanto a la asignación de recursos, para ampliar la inversión en educación, teniendo en cuenta los establecimientos de educación del departamento del Casanare.

\section{OBJETIVOS ESPECÍFICOS}

- Evaluar año por año en el período analizado, cual ha sido la cobertura en el sector educativo del departamento del Casanare, tomando como base los indicadores regionales del número de estudiantes matriculados y la población en edad escolar.

- Realizar análisis financiero vertical a la ejecución presupuestal del departamento del Casanare, en los períodos 1999-2004, con el fin de diferenciar los tipos de ingresos y 
egresos en sector educativo básico primario y secundario.

- Analizar la relación de costos por estudiante, frente al presupuesto destinado a la Educación Básica primaria y secundaria en el departamento del Casanare, en términos del crecimiento real y precios corrientes entre los períodos 1999-2004.

- Diseñar estrategias y/o recomendaciones para que la asignación de los recursos presupuestales en el sector educativo estén acordes con a las necesidades de la región.

\section{JUSTIFICACIÓN}

Esta investigación se realiza para conocer la importancia de la incidencia del gasto público en el sector educativo dentro del presupuesto general del departamento del Casanare, estableciendo indicadores que permitan demostrar la escasa inversión en el sector educativo.

\section{GUÍA PARA LA CONTABILIDAD AMBIENTAL E INFORMES SOCIALES Y MEDIO AMBIENTALES EN LAS EMPRESAS INDUSTRIALES DE VILLAVICENCIO}

\section{Codigo en Biblioteca UNIMETA}

$657.333 \mathrm{H} 26 \mathrm{~g}$

\section{AUTORES}

Blanca Ruth Hernández Tautiva

Lina Mayerly Vega Vásquez

\section{RESUMEN}

La guía para la contabilidad ambiental busca convertirse en una herramienta útil que incida positivamente en la manera de trabajar de las industrias y las introduzca en los conceptos de planeación y gestión ambiental al mismo tiempo que deben servir como instrumento unificador de criterios para las autoridades ambientales.

\section{OBJETIVO GENERAL}

Diseñar y presentar una guía contable ambiental como instrumento alternativo, para las identificaciones y el manejo del control del impacto ambiental, en las empresas industriales de Villavicencio.

\section{OBJETIVOS ESPECÍFICOS}

- Recolectar la información contextual y legal que soporta la gestión medioambiental nacional e internacional como herramienta base de la elaboración de una guía ambiental.

- Identificar los elementos necesarios para el diseño y elaboración de la guía medioambiental.

- Establecer las bases, estrategias y herramientas para el desarrollo de la guía ambiental a aplicarse en las empresas industriales de Villavicencio.

- Plantear las diferencias que se generarían por el manejo ambiental, en la presentación de los estados financieros de la balanza general, el estado de resultado y en el flujo de caja de la empresa.

\section{JUSTIFICACIÓN}

Uno de los propósitos de la política nacional ambiental que enmarcan el proyecto colectivo ambiental del plan nacional de desarrollo, fue la incorporación de las actividades ambientales en los procesos de planeación y gestión de los sectores dinamizadores de la economía nacional; para lo cual el Ministerio de Medio Ambiente, a través de la dirección general ambiental sectorial ha venido promoviendo estrategias, hacia la adopción de buenas prácticas ambientales que conlleven a las sostenibilidad y al mejoramiento de la competitividad empresarial.

\section{DISEÑO E IMPLEMENTACIÓN DE UN MODELO DE PROCESOS PARA EL MANEJO DE LOS BIENES MUEBLES EN SEMILLANO LTDA.}

\section{Codigo en Biblioteca UNIMETA $658.5 \mathrm{R} 46 \mathrm{~d}$}

\section{AUTORES}

\section{Marian Angélica Rincón Aranguren}

Alfredo Fernando Castañeda Camacho

\section{RESUMEN}

La propiedad de la planta y equipo representa una parte importante dentro de una organización dependiendo del tipo de actividad que desarrolle, razón por la cual es conveniente para la administración establecer una serie de controles que permitan un seguimiento efectivo al proceso de estos bienes dentro de la empresa.

\section{OBJETIVO GENERAL}

Definir el procedimiento contable y administrativo a seguir, para salvaguardar la propiedad de planta y equipo en Semillas del Llano LTDA. 
ISSN-2248-736 * Número 3 * Revista Facta Non Verba

\section{OBJETIVOS ESPECÍFICOS}

- Revisar y analizar las cuentas contables de bienes muebles de Semillas del Llano Ltda.

- Sensibilizar al personal de Semillas del Llano Ltda., acerca del control administrativo y financiero a implementar, respecto a la propiedad y planta de la empresa.

- Determinar una estrategia para la implementación de un proceso de control contable y administrativo a los activos fijos de Semillas del Llano Ltda.

- Desarrollar un sistema contable de comprobación de bienes muebles, por responsables de la empresa Semillas del Llano Ltda.

-Elaborar un manual deprocedimientos para elmanejo de losbienesmueblesparalaempresaSemillasdelLlanoLtda.

\begin{tabular}{c}
\hline COMPETENCIA DE LOS CONTADORES \\
PÚBLICOS DE VILLAVICENCIO FRENTE A LAS \\
NORMAS INTERNACIONALES DE \\
CONTABILIDAD DEL SECTOR PRIVADO
\end{tabular}

Codigo en Biblioteca UNIMETA

$657.092 \mathrm{C} 17 \mathrm{c}$

\section{AUTORES}

Leidy Verónica Carvajal Cruz

Claudia Patricia Meneses Medina

\section{RESUMEN}

En la primera parte de este estudio se establece el marco referencial que soporta las Normas Internacionales de Contabilidad (IAS), en la segunda se desarrolla una investigación primaria aplicada a los contadores públicos de Villavicencio, en la tercera se establece una propuesta de competencia que ofrecería las IAS y por último delimita algunas estrategias para la adquisición de conocimiento de las normas internacionales de contabilidad para los contadores públicos de la ciudad de Villavicencio.

\section{OBJETIVO GENERAL}

Realizar un estudio sobre las competencias profesionales de los Contadores Públicos de Villavicencio frente a las normas internacionales de contabilidad, con el fin de identificar las capacidades que adquirirá el profesional.

\section{OBJETIVOS ESPECÍFICOS}

- Describir el marco de las normas internacionales de contabilidad.
- Determinar el nivel de actualización y de conocimiento del contador público de la ciudad de Villavicencio, frente a las normas internacionales de contabilidad.

- Diseñar las competencias profesionales que adquirirá el Contador Público de Villavicencio, desde el punto de vista cognoscitivo, radiológico valorativo y comunicativo, frente a las normas internacionales de contabilidad. - Delimitar algunas estrategias, para la adquisición de conocimientode lasnormasinternacionales de contabilidad, paraloscontadores públicosdelaciudad deVillavicencio.

\section{JUSTIFICACIÓN}

El presente estudio es necesario para poder competir con las economías desarrolladas y por ende buscar nuevos mercados, que mejoren la situación económica de nuestro país, de la región y de la ciudad de Villavicencio, es decir debemos estar acordes con los lineamientos internacionales referentes a la manera como se maneja la información contable en el mundo.

\section{PROYECTO DE ACTUALIZACIÓN NORMATIVA DEL ESTATUTO DE RENTAS DEL MUNICIPIO DE GUAMAL (META)}

Codigo en Biblioteca UNIMETA

336.11 A53p.

\section{AUTORES}

Gloria Esperanza Alfonso Prieto

Elkin Darío Rodríguez Páez

\section{RESUMEN}

Los tributos (impuestos, tasas y contribuciones), implementados por los municipios, son potestativos de los Consejos Municipales, de acuerdo con lo establecido en el numeral 4 del artículo 313 de la Constitución Política. Analizada esta situación consideramos que el Estatuto de Rentas de Guamal, instituido por medio del decreto 110 de 2004, no tiene fundamento legal, ya que éste debe ser establecido mediante un Acuerdo emanado del Consejo Municipal.

\section{OBJETIVO GENERAL}

Analizar el Estatuto de Rentas del municipio de Guamal (Meta), acorde con la normatividad vigente aplicada a los impuestos, tasas y contribuciones administrados por las entidades municipales. 


\section{OBJETIVOS ESPECÍFICOS}

- Establecer si el actual Estatuto de Rentas municipal Decreto 110 de 2004, cuenta con fundamento legal.

- Considerar si los diferentes tributos contenidos en él, se han establecido acorde a la normatividad vigente.

- Manifestar si el municipio puede incorporar en su Estatuto de Rentas municipal, algunos tributos no se han tenido en cuenta para el fortalecimiento de sus ingresos. - Observar si en su Estatuto de Rentas, están incluidos tributos que no cuentan con un fundamento legal.

- Servir de apoyo a la Administración municipal, en la generación de un Estatuto de Rentas que compile las normas tributarias atribuidas a la administración municipal, logrando así una herramienta eficaz con el fin de fortalecer los ingresos municipales y por ende alcanzar el bienestar general y el mejoramiento de la calidad de vida de la población.

\section{JUSTIFICACIÓN}

En Colombia, los municipios se encargan de administrar y gestionar más de quince (15) ingresos de carácter tributario, sin embargo, un $90 \%$ de sus municipios dependen casi exclusivamente de las transferencias; esto se debe entre otras causas a un bajo esfuerzo fiscal, generado por la desactualización de las normas tributarias $\mathrm{y}$ de las bases de datos.

\section{MERCADEO Y PUBLICIDAD}

\section{AÑO 2005}

ESTUDIO DE FACTIBILIDAD PARA EL MONTAJE DE UNA AGENCIA DE PUBLICIDAD EN LA CIUDAD DE VILLAVICENCIO

\section{Codigo en Biblioteca UNIMETA}

$659.1125 \mathrm{C} 65 \mathrm{e}$

\section{AUTORES}

Germán Collazos Ruíz

Carlos Alberto Díaz Girón

\section{RESUMEN}

El presente estudio permitió conocer que existe un gran potencial de clientes que están dispuestos a invertir en sus campañas publicitarias con profesionales de la región, por lo que estarían dispuestos a contratar con una agencia de publicidad de la ciudad de Villavicencio que les garantice la calidad y los costos, debido a que les evitaría el desplazamiento hacia la ciudad de Bogotá, y tener que ajustarse a los tamaños estándar que se manejan en el mercado capitalino.

Lo anterior demuestra con claridad la oportunidad de la puesta en marcha de una agencia, que a través de un servicio eficiente con tecnología y profesionalismo, ayude para que otros negocios se reestructuren y generen un marco de competitividad y calidad más amplio a nivel publicitario para la región.

\section{OBJETIVO GENERAL}

Determinar la factibilidad de constituir una Agencia de Publicidad en la ciudad de Villavicencio.

\section{OBJETIVOS ESPECÍFICOS}

- Realizar un estudio de mercados a través de la aplicación de una encuesta a diferentes empresas del sector económico de la ciudad, para identificar la oferta y la demanda de la industria publicitaria.

- Diseñar el estudio técnico para determinar los aspectos pertinentes para constituir una agencia de publicidad en la ciudad de Villavicencio.

- Elaborar un estudio financiero que determine la viabilidad financiera para la puesta en marcha de una agencia de publicidad en la ciudad de Villavicencio.

\section{JUSTIFICACIÓN}

La economía de la región de los Llanos Orientales, hasta fines del siglo XX era impulsada por los sectores económicos destinados a la ganadería y a la agricultura, como principales y únicas alternativas de desarrollo. Los cambios generados a través del tiempo, traen consigo nuevas exigencias y oportunidades de un mercado que permite para comienzos del siglo, activar el turismo junto con el comercio, como principal fuente económica de la región, y a su vez incrementar en importancia y participación, a los diferentes sectores económicos que lo conforman.

La ciudad de Villavicencio está constituida como una ciudad en pleno desarrollo, $\mathrm{y}$ fortalecimiento económico, en el sector industrial y comercial de la ciudad. "La Puerta del Llano", significa para muchos inversionistas: "la puerta de nuevos negocios en el mercado", nuevos productos, nuevas marcas, nuevas firmas, muchos más servicios y alternativas de elección en busca de satisfacer plenamente las necesidades de los consumidores. 


\section{ISSN-2248-736 * Número 3 * Revista Facta Non Verba}

La necesidad de las empresas de incluir dentro de sus presupuestos una inversión publicitaria, se hace cada vez más notable, debido a que la respuesta que se obtiene por una inversión, genera un margen altamente positivo en cuanto a imagen, posicionamiento y rentabilidad de las empresas.

Con tantos productos y mensajes para comunicar, habrá muchos empresarios que tendrán que escuchar el llamado de la publicidad, y aplicarla dentro de sus acciones comerciales en bien de la prosperidad del negocio, y el sostenimiento en un mercado que presenta una oportunidad de inversión en el campo publicitario, en donde no existe una infraestructura publicitaria basada en el profesionalismo, en la organización empresarial y en la capacidad para atender satisfactoriamente las necesidades del cliente.

TENDENCIA DE CONSUMO ANTIPASTO EN LA CIUDAD DE VILLAVICENCIO

Codigo en Biblioteca UNIMETA 641.812 A38I

\section{AUTORES}

Lorena Agudelo Vargas

Paola Andrea Sabogal

\section{RESUMEN}

El presente estudio pretende determinar las tendencias de consumo de Antipasto en la ciudad de Villavicencio, identificar el tipo de consumidor promedio, las características del producto y demás factores que facilitan el conocimiento en detalle de las principales variables que hacen parte del producto.

\section{OBJETIVO GENERAL}

Realizar un estudio de análisis de las tendencias de consumo de antipasto en la ciudad de Villavicencio.

\section{OBJETIVOS ESPECÍFICOS}

- Establecer el grado de conocimiento del Antipasto.

- Identificar clientes actuales y potenciales.

- Establecer la frecuencia de consumo.

- Conocer si el consumidor identifica alguna marca comercial de Antipasto.
- Medir el grado de intención de compra.

- Establecer preferencias de presentación del producto y de productos acompañantes.

- Determinar los factores de compra más importantes.

\section{JUSTIFICACIÓN}

La presente investigación se encuentra orientada a identificar e interpretar la casualidad originada a partir de los criterios y comportamientos de compra asimilados al proceso de adquisición directa de antipasto; demás, indica y señala las diferentes variables y conceptos económicos que pueden convertirse en objeto de estudio, análisis e interpretación académica.

\section{EVALUACIÓN DE LOS SERVICIOS A DOMICILIO EN LOS EXPENDIOS DE ALIMENTOS EN LA CIUDAD DE VILLAVICENCIO}

\section{Codigo en Biblioteca UNIMETA}

338.4 R81e

\section{AUTORES}

Ángela Rocío Rubio Caicedo

Nadia Jennifer Olarte Umaña

\section{RESUMEN}

La calidad de servicio a domicilio se ha convertido en un factor fundamental en la decisión de compra. Ello tiene varias razones, la más importante es la relación tiempo-costo que es definitoria entre los productos de la misma calidad, pues la gama de productos y servicios a domicilio son cada vez más amplias y el determinar ventajas bajo la relación descrita, hace que se puedan obtener ventas con mayor facilidad, solo si se realiza bajo el marco de conocimiento del mercado servido (CBT), competencia basada en tiempo.

\section{OBJETIVO GENERAL}

Evaluar el servicio a domicilio de los expendios de alimentos en la ciudad de Villavicencio, por medio de la investigación de mercados, con el fin sensibilizar a los comerciantes para el mejoramiento de la calidad de los servicios a domicilio en la ciudad de Villavicencio. 


\section{OBJETIVOS ESPECÍFICOS}

- Identificar la problemática actual del servicio a domicilio ofrecido en los expendios de alimentos en la ciudad de Villavicencio.

- Conocer las expectativas que el cliente espera recibir en el momento de tomar el servicio a domicilio en la ciudad de Villavicencio.

- Determinar cómo se manejan los variables precio, calidad y tiempo por parte de las empresas que prestan el servicio a domicilio en la ciudad de Villavicencio.

- Desarrollar una serie de lineamientos que permitan mejorar la prestación del servicio a domicilio en la ciudad de Villavicencio.

\section{JUSTIFICACIÓN}

La presente evaluación del servicio a domicilio en la ciudad de Villavicencio contribuirá significativamente al desarrollo de las empresas locales, las cuales, con base a este estudio, podrán incorporar la venta a domicilio en el sector comercial con mayores ventajas competitivas, mejorando la calidad de vida de los clientes y aumentando su fidelidad hacia la empresa. Además, por medio del conocimiento de esta forma de venta, se pueden desarrollar estrategias que contribuyan al bienestar económico y social de la comunidad por medio de la satisfacción de las necesidades de los clientes.

AÑO 2006
ESTUDIO DE PREFACTIBILIDAD DEL CONSU-
MO DE YUCA PRECOCIDA EN LA CIUDAD DE
VILLAVICENCIO

Codigo en Biblioteca UNIMETA $633.682 \mathrm{~T} 67 \mathrm{E}$

\section{AUTORES}

Blanca Cecilia Torres Molano

Paola Andrea Guzmán Ruja

\section{RESUMEN}

El estudio de factibilidad para la comercialización de una línea de yuca precocida se desarrolla desde el punto de vista de los mercados, tomando como objeto un sector por explotar y no una empresa en particular. De esta forma se obtienen datos que sirven no sólo a quien pudiese en un momento dado querer invertir en ese tipo de negocio, sino que también se da como fundamentación práctica del desarrollo comercial de un producto para la comprensión de éste en el ámbito local.

\section{OBJETIVO GENERAL}

Determinar la viabilidad comercial de las diferentes líneas de productos precocidos, provenientes de la industria local por medio del análisis del mercado, con el fin de impulsar la industria alimenticia en la ciudad de Villavicencio.

\section{OBJETIVOS ESPECÍFICOS}

- Desarrollar un diagnóstico sobre la situación actual de los productos precocidos en la ciudad de Villavicencio

- Conocer la expectativa del cliente (intermediario y consumidor) con respecto al consumo de productos precocidos fabricados en la ciudad de Villavicencio

- Diseño de estrategias que garanticen un mejor acceso en los mercados de los productos precocidos procedentes de la ciudad de Villavicencio.

\section{JUSTIFICACIÓN}

La realización de esta investigación es importante para los propietarios de empresas cuya actividad permita la implementación de líneas de productos precocidos al igual que para los inversionistas que vean en este tipo de negocio una oportunidad, garantizando así la supervivencia y el desarrollo de la industria alimenticia local, el fomento a la industrialización de materias primas y el desarrollo del valor agregado.

\section{HÁBITOS DE CONSUMO DE LICORES EN VILLAVICENCIO}

Codigo en Biblioteca UNIMETA

$658.834 \mathrm{~T} 67 \mathrm{~h}$

\section{AUTOR}

Carlos Torres Ladino

\section{RESUMEN}

El presente trabajo nos permite identificar los factores de influencia en el comportamiento del consumidor de licores en el municipio de Villavicencio para la satisfacción de necesidades de sus habitantes, además de identificar 
ISSN-2248-736 * Número 3 * Revista Facta Non Verba

sus comportamientos y los niveles de respuestas existentes según el grado de participación en la compra.

\section{OBJETIVO GENERAL}

Analizar los hábitos y tendencias del consumo de licores para que las empresas comercializadoras identifiquen el tipo de licor que prefieren los consumidores de Villavicencio.

\section{OBJETIVOS ESPECÍFICOS}

- Identificar la influencia que tienen los grupos de referencias en el consumo de licores.

- Conocer el grado de aceptación que tiene el consumo de licores en la organización social de Villavicencio.

- Indagar el tipo de licor que consume la familia dependiendo de la celebración.

\section{JUSTIFICACIÓN}

Este estudio servirá para la implementación de nuevas estrategias en la comercialización de los licores, ayudando a su vez al desarrollo de nuevos negocios en este mercado tan competitivo en la expansión comercial de la ciudad; más aún cuando prevé el aumento de las ventas debido a un mayor potencial de clientes dentro de los cuales podemos mencionar a los turistas.

\section{ESTUDIO SOBRE LA APLICACIÓN DE MERCHADISING EN LOS SUPERMERCADOS DE BARRIO DE LA CIUDAD DE VILLAVICENCIO}

\section{Codigo en Biblioteca UNIMETA}

658.8 P $65 \mathrm{e}$

\section{AUTORES}

Viviana Andrea Polo Castro

Jenny Maritza Barrios Rodríguez

\section{RESUMEN}

Este proyecto se centra en la importancia de prestar un servicio atractivo y eficiente en el proceso de comercialización de alimentos y elementos de aseo para el hogar, en donde la aplicación del esfuerzo humano dirigido hacia el punto de venta promueve la calidad de los productos, el manejo de publicidad, el aumento de la demanda y la generación del empleo.
OBJETIVO GENERAL

Analizar las aplicaciones de merchandising que los supermercados de Villavicencio realiza, a la hora de vender sus productos por medio de la utilización de estrategias y técnicas que estimulen la compra en el punto de venta.

\section{OBJETIVOS ESPECÍFICOS}

- Identificar la problemática actual del merchandising en los formatos de supermercados de Villavicencio.

- Conocer las actitudes y expectativas que el cliente tiene y espera recibir con respeto a la exhibición y tiempo en los formatos de supermercado de barrio en la ciudad de Villavicencio.

\section{JUSTIFICACIÓN}

El diagnóstico que se busca realizar con este trabajo de grado pretende señalar las debilidades y fortalezas que poseen los supermercados a la hora de aplicar sus estrategias de merchandising, y a su vez, desarrollar una serie de lineamientos que ayuden a aprovechar de manera óptima la buena aplicación del conjunto de técnicas y estrategias que se manejan con el objetivo de impulsar la compra de los diferentes productos en el punto de venta de los supermercados de la ciudad de Villavicencio.

\section{AÑO 2010}

\section{PLAN DE MARKETING PARA EL BIOPARQUE LOS OCARROS MUNICIPIO DE VILLAVICENCIO}

Codigo en Biblioteca UNIMETA

574.5 C15p

\section{AUTORES}

Tibana Andrea Calvo Hernández

\section{RESUMEN}

En el territorio municipal se identifican diferente ecosistemas que cumplen funciones ambientales precisas y albergan la diversidad de los paisajes, fauna y flora que convierte a esta porción de Colombia en un paraíso natural; fuente inagotable de paisajes, reservas naturales, exóticas faunas, ríos, llanos, selvas, altillanuras, sabanas, y serranía. El Bioparque los Ocarros es un escenario multicampus de primer orden, reconocido por ser eje en la investigación, la educación y la lúdica originada a partir del fomento, protección y conservación de la fauna, flora y los ecosistemas regionales. 


\section{OBJETIVO GENERAL}

Realizar la propuesta de plan de marketing para el Bioparque los Ocarros del municipio de Villavicencio

\section{OBJETIVOS ESPECÍFICOS}

- Realizarunanálisis situacionaldelBioparquelosOcarros - Diseñar estrategias y tácticas del plan de marketing para el Bioparque los Ocarros

-Incrementar las ventas un 3\% respecto al 2009

\section{JUSTIFICACIÓN}

El plan de marketing ayudara a la gestión gerencial del Bioparque los Ocarros, a conocer la situación en el mercado, situación del producto, situación de la competencia, de la distribución y del macro ambiente, para así desplegar estrategias de marketing que le permita desarrollar sus objetivos.

\section{ESCUELA DE DERECHO Y CIENCIAS SOCIALES}

\section{AÑO 2005 \\ COMPARACION NORMATIVA DE LOS TIPOS PENALES DE PECULADO POR EXTENSIÓN Y ABUSO DE CONFIANZA CALIFICADO}

\section{Codigo en Biblioteca UNIMETA}

345.0262/A88c

\section{AUTORES}

\section{Arturo Atuesta Álvarez}

\section{RESUMEN}

Se realiza una comparación entre la estructura normativa de los tipos penales de Peculado por Extensión y Abuso de Confianza Calificado, con el fin de establecer si en realidad el objeto material protegido en el extinto delito es igualmente salvaguardado en el nuevo delito; o si por el contrario, en éste último se busca la tutela de un bien jurídico exclusivo de los particulares, dejando a un lado la protección del patrimonio económico del Estado.
Se concluye que el objeto material protegido mediante el tipo de abuso de confianza calificado guarda identidad con los protegidos en el delito extinto, por lo que se establece de manera clara y precisa, que en ningún momento el legislador desprotegió la salvaguarda de dichos objetos materiales, pues se continúan protegiendo todos los bienes materiales. En el delito de abuso de confianza calificado se protegen los bienes jurídicos del patrimonio económico de los particulares y de la administración pública a través de la guarda de los mismos objetos materiales.

\section{OBJETIVO GENERAL}

Plantear desde el punto de vista jurídico penal, constitucional y administrativo, si la estructura de los tipos penales de los delitos de Peculado por Extensión y Abuso de Confianza Calificado protegen debidamente los bienes del Estado, para luego determinar si las conductas descritas en el primer tipo son susceptibles de ser realizadas en el segundo delito, guardando correlación con el sujeto activo y objeto material protegidos por el legislador al igual que con los limites punitivos.

\section{OBJETIVOS ESPECÍFICOS}

- Establecer una comparación normativa de los tipos de Peculado por Extensión y Abuso de Confianza Calificado

- Determinar si el objeto material del bien jurídico que se tutelaba en el delito de Peculado por Extensión, se protege igualmente en el delito de Abuso de Confianza Calificado.

\section{JUSTIFICACIÓN}

En la actualidad las políticas estatales que establecen los lineamientos de la política criminal, están orientadas a luchar más decididamente contra la corrupción administrativa, ya que esta es un flagelo que corroe las estructuras que cimientan el Estado y la Sociedad Civil, además de retrasar e impedir el desarrollo sostenible de la población colombiana; por lo tanto, es indispensable establecer, después de hacer una comparación normativa de los tipos penales de peculado por extensión y abuso de confianza calificado, si el fin perseguido por el legislador en los delitos contra la Administración Pública del Estado, como es la protección del patrimonio económico del Estado, es susceptible de cumplirse por medio del delito de abuso de confianza calificado, tipo penal que busca la protección del patrimonio económico de los particulares. Y de esta manera establecer la conveniencia o inconveniencia de la supresión normativa del tipo de peculado por extensión, como útil herramienta jurídica para la protección de los bienes públicos y la lucha contra la corrupción administrativa. 


\section{ANÁLISIS COMPARATIVO ENTRE LA JUSTICIA PENAL ORDINARIA Y LA PENAL MILITAR A LA LUZ DE LOS PRINCIPIOS DE IGUALDAD Y FAVORABILIDAD}

Codigo en Biblioteca UNIMETA

340.11. S63A

\section{AUTORES}

Martha Fernanda Sogamoso Sánchez Zully Alexandra Hernández Díaz

\section{RESUMEN}

En un país como Colombia, en el cual existe un sin número de normas jurídicas, que no tienen vigencia en la realidad, cualquier esfuerzo investigativo por darles vida es válido. Es claro que en un Estado Social de Derecho, bajo ninguna circunstancia, los militares pueden juzgar a los civiles y correlativamente cuando aquellos cometan algún acto propio de su naturaleza castrense, se les debe garantizar el fuero, según el cual serán investigados por sus superiores.

No obstante, hay algo que no se puede pasar por alto y es que los miembros de la fuerza pública son tan humanos como cualquier civil y no siempre están en actitud de servicio; también ejecutan actividades cotidianas, las que en una sociedad de riesgo como en la que vivimos pueden llegar a constituir Conductas Punibles de una entidad menor, que facilitan una serie de formas anormales de terminación del proceso penal, en las cuales ganan tanto la víctima como el imputado.

Es a ello a lo que apunta esta investigación, promover la utilización del principio de Integración, para aquellos casos no reglados por la Ley Penal Militar, en los que la codificación penal ordinaria, sustancial y adjetiva posibilitan la aplicación de figuras jurídicas como la Conciliación y la Indemnización Integral. También se propone la reconsideración de estamentos como el Grado Jurisdiccional de Consulta, los que procesalmente según su diseño, resultan violatorios de los principios de Igualdad, Favorabilidad e Integración.

\section{OBJETIVO GENERAL}

Realizar un diagnóstico comparativo entre los institutos procedimentales de detención preventiva, sentencia anticipada, indemnización integral, grado jurisdiccional de consulta y conciliación de origen constitucional consagrados en la legislación penal ordinaria y aquellos establecidos en la codificación penal militar, tomando como marco de referencia los principios rectores de igualdad y favorabilidad, con el propósito de formular una serie de propuestas hermenéuticas y procedimentales, enfocadas a garantizar para los miembros de la fuerza pública un tratamiento igualitario en comparación al proporcionado a los civiles, cuando los supuestos fácticos así lo permitan.

\section{OBJETIVOS ESPECÍFICOS}

- Exponer los fundamentos constitucionales de la jurisdicción penal militar como mecanismo de control social. - Fomentar una reflexión crítica, respecto al diseño y los contenidos sustanciales que debe tener en cuenta el legislador penal militar, al momento de establecer los estatutos procesales, en aras de garantizar los derechos de la igualdad, la favorabilidad y el debido proceso del que son titulares, así sea en forma especial los miembros de la fuerza pública.

- Analizar algunas hipótesis en las que el tratamiento procesal que recibe un miembro de la fuerza pública, resulta desigual comparado con el que se brinda a un civil, cuando ambos actúan en idénticas circunstancias de motivación. Específicamente se analizan los más importantes delitos querellables contemplados en la jurisdicción penal ordinaria art. 74 Ley 906 de 2004.

- Analizar la utilidad del principio de integración, las excepciones de inconstitucionalidad, la analogía y la hermenéutica constitucional, como herramientas encaminadas a solucionar los problemas que se van a plantear.

\section{JUSTIFICACIÓN}

En materia penal prima la Jurisdicción Ordinaria para la investigación y juzgamiento de las conductas punibles. Sin embargo, durante la historia de la humanidad ha sido indispensable separar los comportamientos ilegales cometidos por los civiles de aquellos en los que puedan incurrir los miembros de la Fuerza Pública; en el caso colombiano, Ejército Nacional, Armada Nacional, Fuerza Aérea Colombiana y Policía Nacional, cuando los mismos estén directamente relacionados con el servicio o sean consecuencia de este.

Para el tratadista Luis Carlos Sáchica, en el Constituyente de 1991 en su Art. 216 y a su turno en el Art. 221 de la carta, adicionado por el acto legislativo No. 2 de 1995, 
se creó una jurisdicción especial diferente a la ordinaria, situación que a su vez es la contraposición a la prohibición consagrada en el último inciso del Art. 213 ídem, en virtud de la cual los militares bajo ninguna circunstancia podrán juzgar civiles.

Teniendo en cuenta el soporte constitucional de esta Jurisdicción especial, es menester señalar que en lo no reglado por ella en forma expresa, se previó la posibilidad de aplicar el principio de integración con las disposiciones punibles ordinarias (sustantivas y procedimentales), condicionado a que tal proceder no sea contrario a la naturaleza misma del Derecho Penal Militar; por ello se hace necesario delimitar cuales son las características comunes de los dos ordenamientos represores y cuáles son las propias de la Legislación Penal especial que en principio imposibilitarían las maniobras de integración.

\section{EL TRATADO DE LIBRE COMERCIO A LA LUZ DEL DERECHO AMBIENTAL COLOMBIANO: Aproximación crítica al futuro manejo de los recursos hídricos en la región de la Orinoquía.}

Codigo en Biblioteca UNIMETA

382 P $17 \mathrm{t}$

\section{AUTORES}

Parrado Rojas Luz Myriam

\section{RESUMEN}

Se realiza una aproximación crítica a los postulados del Tratado de Libre Comercio -en negociación- a celebrar entre Colombia y Estados Unidos para identificas aspectos nodales en los cuales se encuentre latente la posibilidad de comprometer las fuentes hídricas colombianas. Se establece que en el TLC existen postulados que, no expresamente pero si entre líneas, abren las puertas a la privatización de las fuentes hídricas, a través de contratos con las transnacionales para la explotación de bosques con fines comerciales, prestación de servicios de administración de parques y zonas de reserva natural con usufructo comercial por parte de empresas de capital extranjero.

Resulta claro que no es factible la privatización de fuentes hídricas o del agua colombiana bajo ningún escenario, entendida esta como la titulación de cuencas o ríos a entes privados nacionales o extranjeros. Sin embargo, es inminente que entes privados utilizarán y aprovecharán las fuentes hídricas a través de concesiones con propósitos lucrativos, ya que la normatividad colombiana lo ha dispuesto para el sector privado nacional, y el TLC busca que en las mismas condiciones de favorabilidad entren las nuevas inversiones. Colombia está obligada a aprovechar las ventajas geoestratégicas y comparativas que posee en este aspecto, a proteger tal riqueza, y a revertir lo que ha sucedido en el pasado.

\section{OBJETIVO GENERAL}

Discutir los efectos que puede generar el Tratado de Libre Comercio con Estados Unidos frente al manejo de las fuentes hídricas en la Región de la Orinoquía.

\section{OBJETIVOS ESPECÍFICOS}

- Discutir si las fuentes hídricas nacionales se están comprometiendo en el Tratado de Libre Comercio Colombia - Estados Unidos.

- Discutir si es factible jurídicamente que se privaticen las fuentes hídricas colombianas a partir del Tratado de Libre Comercio con Estados Unidos.

- Discutir el futuro de las fuentes hídricas en la región de la Orinoquía.

\section{JUSTIFICACIÓN}

La pregunta que orientó este ejercicio de investigación fue la siguiente: ¿Cuáles son los efectos que puede generar el Tratado de Libre Comercio con Estados Unidos en el manejo de las fuentes hídricas en la región de la Orinoquía? Se establece a priori que la tendencia es hacia la privatización del agua y en este escenario la región de la Orinoquía puede verse fuertemente afectada por la importancia hídrica que representa en Colombia y en la región.

El Tratado de Libre Comercio -en negociación- presenta varios postulados, tanto en el capítulo de inversiones como en los de servicios y asuntos ambientales, en los cuales aparece entre líneas, la posibilidad de comprometer no solo los recursos naturales en general sino el agua en particular. Es necesario entonces identificar si en la negociación comercial con Estados Unidos se encuentra latente la posibilidad de comprometer las fuentes hídricas, es decir, si es posible la inclusión de las aguas en los acuerdos comerciales. Igualmente es importante saber si es factible jurídicamente que se privaticen fuentes hídricas colombianas a partir del Tratado de Libre 
ISSN-2248-736 * Número 3 * Revista Facta Non Verba

Comercio con Estados Unidos. En este contexto y una vez realizados las interpretaciones del caso se lanzan las sospechas que se tienen frente al futuro manejo de las fuentes hídricas a partir del TLC y se identifican, a grandes rasgos, los efectos que ello genera en la región de la Orinoquía.

\section{AÑO 2006}

\section{LA LIBERTAD COMO LÍMITE MATERIAL DEL IUS PUNIENDI}

Codigo en Biblioteca UNIMETA

323.44 D871

\section{AUTORES}

Helena María Duque Cabrera

Christian Alexander Pérez Jiménez

\section{RESUMEN}

Los Estados Sociales de Derecho tienen como cimiento el establecimiento y cumplimiento de los derechos fundamentales de sus asociados. Sin embargo, esta afirmación no pasa de ser un juicio del deber ser en la mayoría de Estados Americanos, ya que de pronto, el Estado puede estar haciendo uso del IUS PUNIENDI o poder punitivo del Estado, de manera desmedida y subjetiva. Se realizó una investigación descriptiva fundamentada en estadísticas del número actual de presos sin estar condenados en Villavicencio, incluyendo un análisis comparativo de las leyes 600 de 2000 y la ley 906 de 2004. Se plantea la hipótesis de que el Estado colombiano está avanzando en la consolidación del Estado Social y Democrático de Derecho, donde priman los derechos fundamentales, entre ellos la libertad sobre el poder punitivo del Estado.

Se demuestra que la libertad "debe ser" un límite material del IUS PUNIENDI aun cuando formalmente ya está consagrada como tal, ya que la Ley 906 de 2004 establece que para violar este derecho fundamental debe mediar orden judicial. Sin embargo, se observa con preocupación que en la cárcel de Villavicencio es mayor el número de presos sin condena, es decir, que están en las cárceles en virtud de una detención preventiva, mientras que es menor el número de presos que pagan condena.

\section{OBJETIVO GENERAL}

Elaborar una herramienta práctica dirigida a estudiantes y litigantes para dar a conocer la libertad como límite material del IUS PUNIENDI.

\section{OBJETIVOS ESPECÍFICOS}

- Realizar un análisis histórico dogmático de la libertad respecto al derecho penal en las diferentes clases de Estado que ha tenido la sociedad.

- Hacer un análisis comparativo entre la Ley 600 de 2000 y la Ley 906 de 2004 en lo que respecta a la detención preventiva y la libertad.

- Establecer a través de las estadísticas el número actual de presos sin estar condenados en el Distrito Judicial de Villavicencio, para poder demostrar la realidad de muchas personas privadas de la libertad.

\section{JUSTIFICACIÓN}

Esta investigación busca definir parámetros claros para prevenir y corregir el ejercicio de medidas preventivas de aseguramiento por parte de funcionarios judiciales que actúan irresponsablemente, tal vez guiados por una concepción errónea y costumbrista del derecho penal más que por una posición dogmática, incurriendo en delitos como privación ilegal de la libertad y otros tantos, que a la postre no son investigados y mucho menos juzgados por las autoridades competentes.

Al mismo tiempo se busca brindar una herramienta práctica a estudiantes y litigantes para el ejercicio del derecho penal tomando como base principios y normas fundamentales que están inmersas en la normatividad colombiana, logrando de esta forma el cumplimiento de muchos postulados, como la dignidad humana, la libertad, el debido proceso, la presunción de inocencia entre otros, al momento de ejercer la defensa de personas que han o no infringido la Ley Penal y garantizando el correcto funcionamiento del aparato jurisdiccional. De ahí la necesidad de establecer la libertad como límite material del IUS PUNIENDI.

\author{
Facta Non Verba \\ Revista
}




\section{ANÁLISIS DE LAS FUNCIONES DEL JUEZ DE CONTROL DE GARANTÍAS EN DEFENSA DEL DERECHO FUNDAMENTAL AL DEBIDO PROCESO}

Codigo en Biblioteca UNIMETA

347.014 p26a

\section{AUTORES}

Jaqueline Pinto Rozo

Adilia Godoy García

\section{RESUMEN}

Por primera vez en el sistema penal colombiano se adopta en su integridad el Modelo Penal Acusatorio y por ende se crea la figura del Juez de Control de Garantías con sus funciones principales de control de legalidad y constitucionalidad de la investigación, y la adopción de medidas que impliquen la limitación de derechos fundamentales. Se analizan las funciones del Juez de Control de Garantías en especial con el debido proceso y el principio de lealtad procesal.

Se establece la importancia de la creación de la figura del Juez de Control de Garantías por cuanto este está llamado a ser imparcial y tratar de equilibrar la obligación estatal de investigar y el derecho fundamental al debido proceso. Otro avance es la concepción de excepcionalidad de las medidas de aseguramiento y la actual clasificación en restrictivas y no restrictivas de la libertad. El principio de gradualidad trae implícito la posibilidad de abstenerse de restringir la libertad en institución carcelaria, cuando en el imputado concurren las circunstancias especiales de que trata el artículo 314 del C.P.P. Igualmente se establece que el control anterior y posterior de las medidas de aseguramiento es una de las principales funciones del juez de control de garantías, ya que en ejercicio de esta facultad, este juez se convierte en juez constitucional.

\section{OBJETIVO GENERAL}

Analizar las funciones del Juez de Control de Garantías y establecer si con estas se permite el efectivo cumplimiento del derecho fundamental al debido proceso.

\section{OBJETIVOS ESPECÍFICOS}

- Describir jurídico-penalmente las funciones del juez de control de garantías.

- Describir jurídico-penalmente el principio constitucional del debido proceso.
- Analizar la figura del juez de control de garantías en relación a su posición de garante del principio constitucional al debido proceso.

\section{JUSTIFICACIÓN}

La implementación de un esquema de tendencia acusatorio en el sistema penal colombiano, implica una radical transformación de la dinámica del proceso penal y la descripción de sus elementos básicos. La introducción del modelo acusatorio comporta una redefinición del concepto de verdad. En términos generales, el modelo inquisitivo se basa en la obligación del Estado de buscar la verdad y a partir de ella imponer las sanciones o mantener la inocencia de la persona investigada. Es decir, la verdad se entiende como algo existente y que debe ser objeto de búsqueda. El investigado no tiene que aportar pruebas a su favor sino que ha de limitarse a cuestionar la verdad encontrada por el Estado.

Por el contrario, el modelo acusatorio se basa en la construcción de la verdad. Las partes llegan al juicio con visiones de la realidad y será la confrontación entre tales visiones la que determine lo que se considera verdadero. Adquiere entonces gran importancia el convencimiento del Juez y en especial el del Juez de Control de Garantías quien ejerce dos funciones básicas: El control de legalidad y constitucionalidad de la investigación, y la adopción de medidas que impliquen la limitación de derechos fundamentales.

Siendo la figura del juez de control de garantías nueva para el sistema penal colombiano, es de invaluable importancia el estudio de esta figura y la determinación del alcance de sus funciones en directa relación con los derechos fundamentales y en especial con el debido proceso y el principio de lealtad procesal.

\section{NORMAS TÉCNICAS Y RESPONSABILIDAD SOBRE LA CALIDAD DE AGUA POTABLE EN VILLAVICENCIO}

Codigo en Biblioteca UNIMETA

333.9122 M17n

\section{AUTORES}

Luis Eduardo Marín Gómez

José Luis Arciniegas Galindo

\section{RESUMEN}

El suministro de agua potable es un servicio público a 
ISSN-2248-736 * Número 3 * Revista Facta Non Verba

cargo del Estado, aunque lo pueden prestar también los particulares. Se pretende auscultar si en Villavicencio se consume agua potable o no, quiénes son los responsables del incumplimiento de las normas de calidad de agua potable, si hay incumplimiento, que consecuencias para la salud tiene esa mala calidad y que puertas judiciales quedarían abiertas para hacerlas cumplir.

Se establece que las aguas de los dos acueductos muestreados no son potables; entre las consecuencias originadas por la mala calidad del agua se encuentran infecciones en vías digestivas, respiratorias y de piel. Es notoria la falta de control y vigilancia por parte de las entidades responsables de la calidad de agua potable. Los responsables de los daños causados a los usuarios por la calidad del agua son los prestadores del servicio en forma directa, los personeros municipales, la superintendencia de servicios públicos, las secretarías de salud, el municipio, el departamento, la nación, la comunidad organizada y el consumidor final. Se deben implementar las siguientes acciones para obtener el derecho al agua potable o para lograr la indemnización de los daños por la mala calidad del agua: acción de tutela, acción de cumplimiento, acción de reparación directa, acciones de grupo, acciones populares, derecho de petición y queja disciplinaria.

\section{OBJETIVO GENERAL}

Indicar cuales son las exigencias legales sobre la calidad del agua potable para consumo humano y cotejarlas con las características del agua de dos de los acueductos más grandes de Villavicencio.

\section{OBJETIVOS ESPECÍFICOS}

- Determinar las exigencias sobre calidad del agua potable para consumo humano que establece la ley. Solicitar los resultados de las últimas muestras tomadas a los dos acueductos más grandes de Villavicencio, para compararlas con las exigencias legales. Puntualizar las discordancias obtenidas en la comparación.

- Hacer un breve estudio de las incidencias de las discordancias, si las hay, sobre la salud de la población.

- Determinar las responsabilidades que le correspondan a cada una de las personas que prestan, vigilan y controlan el sistema de suministro de agua y su calidad.

- Hacer un breve análisis de las acciones judiciales que tienen los usuarios para garantizar el suministro de agua potable.

\section{JUSTIFICACIÓN}

Esta investigación es justificable porque se indica cuáles son las exigencias organolépticas, físicas, químicas y microbiológicas de la calidad del agua potable que la ley determina, si el agua de Villavicencio cumple o no esas exigencias, cuáles son las exigencias que no cumple, cuáles son las consecuencias para la salud del incumplimiento de esas exigencias y quienes son los responsables del cumplimiento de las normas de calidad, de la vigilancia y control de esa calidad.

\section{IMPACTO JURÍDICO SOCIAL DEL SISTEMA PENAL ACUSATORIO EN COLOMBIA}

\section{Codigo en Biblioteca UNIMETA 345 G88i}

\section{AUTORES}

\section{RESUMEN}

Esta investigación de carácter educativo pretende hacer un aporte al desarrollo y evolución de la implementación del sistema penal acusatorio, para que, cuando entre a funcionar en la ciudad de Villavicencio, se tenga la capacidad ilustrativa y experimental para enfrentar dicho sistema.

Se encuentran situaciones que llevan en dirección contraria a la finalidad del actual sistema acusatorio, entre otras las siguientes:

- Se necesita un cambio en las formas culturales de formación, aplicación y comprensión del derecho penal; por ejemplo, la igualdad de las partes intervinientes, la libertad personal como regla general, las penas alternativas o las formas de negociación del conflicto entre Fiscalía e imputado.

- No se cumple con la consigna de tener la libertad personal como regla general.

- Implica una infraestructura adecuada que conlleva a una alta inversión económica

- El material probatorio debe estar rigurosamente custodiado y protegido, lo que requiere la formación de personal técnico, realización de protocolos y lugares adecuados y seguros para la custodia.

- Un alto porcentaje de procesos solo ha resuelto situaciones de flagrancia y delitos considerados de baja gravedad. - Supone el fortalecimiento de la defensoría pública para asistencia de personas vulnerables por su situación económica. 
- Es un proceso comunicativo altamente deficiente, en el que las personas involucradas no comprenden a la Fiscalía, lo que implica una violación estructural de derechos humanos de los implicados.

- No se encuentra la incidencia de acuerdos entre Fiscalía e imputados.

\section{OBJETIVO GENERAL}

Medir el alcance de la reforma al sistema penal acusatorio en el contexto del derecho, de la cultura judicial y con relación a las garantías de las personas incursas en investigaciones criminales.

\section{OBJETIVOS ESPECÍFICOS}

- Exponer cual es el sentido político, cultural y jurídico del propósito de la reforma introducida por el sistema penal acusatorio.

- Determinar si efectivamente la normatividad cumple con el propósito.

- Analizar algunas hipótesis donde se haya aplicado el sistema penal acusatorio, para determinar la efectividad del mismo en la administración de justicia.

- Establecer una reflexión crítica respecto al contenido dogmático del sistema penal acusatorio.

\section{JUSTIFICACIÓN}

La ineficacia del proceso penal colombiano frente a las altas cifras de impunidad, la mora en los procesos, la ausencia o deficiencia de la investigación, impulsaron reformas al sistema penal. Por ello mediante Acto Legislativo No. 3 de 2002, se modificaron los artículos 250 y 252 de la Constitución para definir el nuevo sistema penal acusatorio y para modificar las funciones asignadas a la Fiscalía General de la Nación. La reforma constitucional dejó en claro que la principal función de la Fiscalía General de la Nación es la de adelantar el ejercicio de la función penal e investigar hechos que podrían constituir conductas delictivas.

La presente investigación se realizó para aportar reflexiones teóricas y prácticas dentro de un contexto crítico sobre elementos esenciales del sistema acusatorio, desde la perspectiva probatoria y la dinámica propia de las audiencias orales.

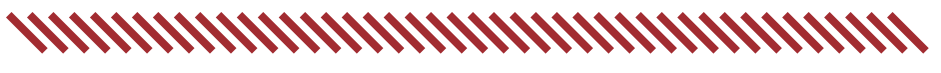

\section{COOPERATIVAS Y PRECOOPERATIVAS DE TRABAJO ASOCIADO FRENTE AL DERECHO LABORAL}

Codigo en Biblioteca UNIMETA

346.0668 A72c

\section{AUTORES}

Hugo Alfonso Archila Suarez

Manuel Alejandro Lozano Correa

\section{RESUMEN}

El gobierno colombiano a través de la Ley 79 de 1998, actualizó la legislación cooperativa confirmando la existencia de las Cooperativas de Trabajo Asociado (C.T.A.) y las Precooperativas de Trabajo Asociado (PC.T.A.) Esta investigación pretende establecer si la legislación establecida para las C.T.A. y PC.T.A, logran vulnerar los derechos laborales (contrato de trabajo, prestaciones sociales, seguridad social en salud, riesgos profesionales, pensiones y sindicalización laboral) de una forma anormal.

Se concluye que, entre otros:

- La legislación establecida para las C.T.A. y PC.T.A, tiende a la deslaboralización del derecho y desprecia el trabajo humano subordinado, por cuanto la relación beneficiarios -C.T.A.- asociados cooperados, no se rige por el derecho laboral.

- Se viola el derecho constitucional de la igualdad y el trabajo digno, ya que mediante las C.T.A. y PC.T.A, se exime a los nuevos trabajadores de disfrutar de las mismas garantías laborales y compensatorias que nuestros ancestros y algunos afortunados trabajadores.

- Las C.T.A. y PC.T.A garantizan más la ocupación que el empleo, constituyéndose en una de las formas de obtener lucro capitalista.

-En la legislación para las C.T.A.yPC.T.A, hay vacíosque permitenladesviacióneindebidautilizacióndelasnormas. - Se propone crear un grupo de gestión que se dedique única y exclusivamente al control de las C.T.A. y las empresas usuarias respectivamente. Igualmente se propone que debe prestarse mayor atención por parte del Ministerio de Trabajo y Protección Social, la Supersolidaria, la Cámara de Comercio para ejercer un control previo y preferente al momento de la etapa de legalización en lo que les concierne con respecto a las C.T.A. y PC.T.A (estatutos y demás documentos y trámites). 


\section{OBJETIVO GENERAL}

Realizar un manifiesto de contenido jurídico relacionado con el contrato de trabajo frente al manejo de las C.T.A. y PCT.A., como guía para reconocer y revelar la conveniencia o inconveniencia de la legislación establecida para las C.T.A. y PC.T.A., o de estas mismas para el derecho laboral y para la sociedad, por cuanto presuntamente vulneran los derechos laborales y distorsionan el verdadero vínculo laboral que se establece entre el sector empresarial y los asociados.

\section{OBJETIVOS ESPECÍFICOS}

- Establecer las ventajas y desventajas de la implementación del uso de personal a través de las C.T.A. y PC.T.A. en cuanto al aspecto laboral, económico y social, tanto a nivel de quienes prestan su mano de obra como de las empresas colombianas.

- Determinar si la legislación cooperativa está lo suficientemente estructurada y no da lugar a que se vulneren los derechos y obligaciones consagradas en la legislación laboral y constitucional, o si en su lugar es falta de control estatal sobre las C.T.A. y PC.T.A. e igualmente sobre las empresas y patronos que acudan a sus servicios. - Realizar un análisis jurídico del desarrollo de la legislación y uso de las C.T.A. y PC.T.A, frente al derecho y realidad laboral colombiana.

\section{JUSTIFICACIÓN}

Colombia revela una tendencia por parte de la comunidad trabajadora dependiente dirigida a la satanización de la legislación cooperativa, producto del manejo de las C.T.A. y PC.T.A, pues al parecer se convirtieron en el mecanismo idóneo para que los empleadores se eximan de sus obligaciones patronales.

En la región es alarmante la manera como los empleadores de algunas empresas, para el caso en el ámbito privado (clínicas, empresas transformadoras de palma de aceite, empresas de telecomunicaciones y mensajería etc.), vienen manifestando, como requisito "Sine qua non" para que su personal tanto nuevo como antiguo pueda laborar en sus empresas, que los primeros se vinculen a C.T.A. y PC.T.A, logrando mediante maniobra administrativa la renuncia voluntaria de los trabajadores, vinculándolos posteriormente a una C.T.A. y PC.T.A y a través de esta continuar trabajando en su empleo habitual, so pena de perder el mismo.

En ocasiones, al parecer estas C.T.A. y PC.T.A, son gestionadas informalmente por los empleadores o grandes empresas, con el fin de salvaguardar el gasto prestacional generado por los derechos laborales de un trabajador normal, situación que alarma el entorno laboral de la región.

\section{LAACCIÓN DE TUTELA Y SU IMPLICACIÓN EN LA CONGESTIÓN DE LOS DESPACHOS JUDICIALES DEL MUNICIPIO DE VILLAVICENCIO}

Codigo en Biblioteca UNIMETA

347.053 B11a

\section{AUTORES}

Bacca Calderón Hernán

Butrabi Castillo Teófilo

\section{RESUMEN}

En Colombia con la constitución nacional de 1991 aparece la tutela como un mecanismo idóneo en defensa de los derechos fundamentales. Sin embargo, esta figura jurídica en los últimos años se ha venido utilizando indiscriminadamente en pro de obtener de manera inmediata servicios que podrían obtenerse por otras vías legales. Se plantea que el uso inadecuado de la acción de tutela ha contribuido con el congestionamiento de los despachos judiciales en la ciudad de Villavicencio. Se utilizaron fuentes de información primaria como las estadísticas de los despachos judiciales, y de información secundaria.

Se detectó que un alto porcentaje de la acción de tutela es negado, por cuanto, según el criterio del juez, existen otros mecanismos jurídicos que se deben agotar antes de iniciar la acción de tutela. Sin embargo, el hecho de poner en marcha el aparato de la justicia para proteger derechos supuestamente violados, ha hecho que los despachos judiciales deban ocupar gran parte de su tiempo en estos procesos, contribuyendo con esto al estancamiento de otros. Se debe reglamentar el uso de la acción de tutela, creándole requisitos de procedimiento y algún tipo de condena en costos a las personas que la utilicen en forma irracional. Por otra parte, es urgente la implantación de un solo modelo de proceso civil, que sea más rápido, claro y expedito, tal como ocurre con el nuevo sistema penal que se aplicará en Villavicencio a partir del próximo año.

\section{OBJETIVO GENERAL}

Determinar la utilización de la Acción de Tutela y su implicación en la congestión de los Despachos Judiciales del Municipio de Villavicencio.

\section{OBJETIVOS ESPECÍFICOS}

Hacer una recopilación teórico- práctica sobre el concepto, origen y antecedentes de la acción de tutela como mecanismo de protección de los derechos fundamentales. 
- Realizar un estudio comparativo de la utilización de la acción de tutela como mecanismo de protección de los derechos fundamentales en Colombia y en otros países. - Establecer a través de estadísticas emanadas de los despachos judiciales del municipio de Villavicencio, la utilización de la acción de tutela como mecanismo de protección de los derechos fundamentales.

\section{JUSTIFICACIÓN}

El mecanismo de acción de tutela le ha dado a la constitución política de 1991 un carácter moderno, democrático, convirtiéndose así en un instrumento eficaz, que pese a ciertos excesos, ha sido el principal apoyo de muchos ciudadanos colombianos que han encontrado en este instrumento la manera de hacer respetar sus derechos.

Sin embargo, en la gran mayoría de los casos es el mismo Estado quien se encarga de obligar al ciudadano a tomar el camino de la acción de tutela como extrema ratio, al sentir que de otra manera nunca tendrá acceso a la aplicación de justicia.

La importancia de este estudio radica en dar a conocer el uso indiscriminado que se le ha dado a la acción de tutela como mecanismo para que se reconozcan los derechos vulnerados de los ciudadanos de Villavicencio y la influencia que ha tenido en el congestionamiento de los despachos judiciales de este municipio.

\section{EL PRINCIPIO DE OPORTUNIDAD DENTRO DEL NUEVO SISTEMA PENAL ACUSATORIO \\ - Impunidad o descongestión.}

\section{Codigo en Biblioteca UNIMETA}

$345684 \mathrm{p}$

\section{AUTOR}

\section{Juan Carlos Cujar Aranguren}

\section{RESUMEN}

El Principio de Oportunidad es definido como la oportunidad otorgada a la Fiscalía General de la Nación para suspender, interrumpir o renunciar a la persecución penal de los autores y partícipes en hechos que revistan las características de una conducta punible. Para comprender esto, es necesario conocer el concepto y evolución jurídica del Principio de Oportunidad, cómo se ha regulado en el derecho comparado y cómo se consagró constitucional y legalmente en Colombia, cómo se ha tratado hasta hoy jurisprudencialmente y qué efectos tiene frente al principio de legalidad.

Un sector de la doctrina opina que el Principio de Oportunidad termina con la hipocresía del Estado, que sostenido en el Principio de Legalidad aseguraba perseguir todos los delitos, cuando en realidad se concentraba en aquellos que no afectaran intereses económicos o políticos. El principio de oportunidad seria entonces una forma de admitir que el Estado es incapaz de perseguir todas las conductas criminales, y podría evitar la selección arbitraria que se efectúa en el sistema judicial, al contemplar expresamente los casos en que el Estado renuncia a la persecución penal. Sin embargo, el principio de Oportunidad guarda en su esencia misma un fundamento que podría igualmente tacharse de hipócrita, o al menos contradictorio. De un lado, el Estado criminaliza una serie de conductas en el Código Penal y posteriormente eleva todas las penas; de otro, descriminaliza esas mismas conductas en el Código de Procedimiento Penal. Todo ello deja la sensación de que se desea engañar al ciudadano, haciéndole creer que lo que las leyes penales condenan será efectivamente juzgado por el Estado. Existen herramientas más eficaces de descriminalización que pueden implementarse desde el derecho penal sustancial, y que no atentan contra algo tan valioso y tan urgente en Colombia como la credibilidad en el sistema judicial y el respeto a la ley. De la confianza que el ciudadano tenga en la justicia y de la protección que sienta del Derecho depende la seguridad del Estado, más que de la acción represiva o el uso de la fuerza.

\section{OBJETIVO GENERAL}

Analizar el principio de Oportunidad contenido en el nuevo Código de Procedimiento Penal que establece el sistema acusatorio de Colombia, imponiéndose un sistema ajeno a nuestra cultura, por cuanto este sistema tiene un hondo raigambre en culturas más respetables del concepto de verdad y donde la mentira es gravemente castigada. En nuestro medio a pesar de haberse modificado el Código Penal para hacer más gravoso el falso testimonio, no tenemos esa cultura de la verdad y podrían cometerse con la aplicación de este instrumento, grandes injusticias.

\section{OBJETIVOS ESPECÍFICOS}

- Analizar si el Principio de Oportunidad consagrado en el nuevo Código es inconstitucional frente al principio de legalidad y a la posibilidad de hacerlo directamente la Fiscalía sin el control previo en algunos casos, como 


\section{ISSN-2248-736 * Número 3 * Revista Facta Non Verba}

está previsto en la Resolución 06657 del 30 de Diciembre de 2004 por medio de la cual se reglamenta la aplicación del principio de oportunidad y en los casos en los cuales conocerá directamente, es decir sin acudir previamente al juez de control de garantías para su declaratoria. - Determinar si el Principio de Oportunidad es fuente de descongestión o de impunidad.

\section{JUSTIFICACIÓN}

La reforma procesal penal es el cambio más trascendental y con mayores consecuencias que ha tenido el sistema de justicia penal. El Principio de Oportunidad consagrado en el nuevo Código de Procedimiento Penal es aplicado actualmente en algunos distritos judiciales del país y será aplicado en nuestro medio en el próximo año (2007) cuando entre en vigencia el sistema acusatorio en el departamento del Meta y Antioquia, Cundinamarca, Florencia, Ibagué, Neiva, Pasto, Popayán y Villavicencio. El principio de oportunidad está siendo aplicado en el eje cafetero y Bogotá desde enero del 2005 y a partir de enero del presente año en Bucaramanga, Buga, Cali, Medellín, San Gil, Santa Rosa de Viterbo, Tunja y Yopal, donde está vigente el sistema acusatorio y de allí se puede deducir si efectivamente este puede descongestionar los despachos judiciales sin que pueda generar a su vez un alto grado de impunidad.

\section{LA VIOLENCIA INTRAFAMILIAR Y LA INASIS- TENCIA ALIMENTARIA ATENTADOS CONTRA LA SOCIEDAD}

Codigo en Biblioteca UNIMETA

$362.8292 \mathrm{G} 65 \mathrm{v}$

\section{AUTORES}

William Gómez Sierra

Iván Gutiérrez Granados

\section{RESUMEN}

La violencia intrafamiliar es un tema que en los últimos años ha crecido notablemente en Colombia. Se estudia la inasistencia alimentaria como causa de violencia intrafamiliar; este problema no distingue esferas sociales, edad, sexo, y sus efectos se reflejan mediante diferentes modalidades ejercidas en el seno del hogar y que repercuten en toda la sociedad.
Se realiza una descripción de los principales estudios realizados sobre violencia intrafamiliar en Colombia, encontrándose altos índices de violencia intrafamiliar e inasistencia alimentaria. Las principales leyes, normas y políticas contra la inasistencia alimentaria son muy débiles frente a este delito. La conciliación en materia de violencia intrafamiliar debe manejarse con un enfoque orientado a la construcción de acuerdos que permitan el restablecimiento de los derechos vulnerados, con criterios de justicia y equidad. El origen familiar y la igualdad de derechos y obligaciones son importantes para exigirlos en todo proceso de inasistencia alimentaria para evitar desigualdad y discriminación.

\section{OBJETIVO GENERAL}

Explorar sobre la inasistencia alimentaria como causa de violencia intrafamiliar y proponer alternativas de aplicación respecto a la concurrencia de este delito y su prevención.

\section{OBJETIVOS ESPECÍFICOS}

- Indagar sobre la violencia intrafamiliar en Colombia, sus causas, teorías, estadísticas y sus consecuencias.

- Identificar las principales leyes, normas y políticas contra la inasistencia alimentaria.

- Establecer si las políticas aplicadas a la inasistencia alimentaria son las adecuadas y proponer alternativas de solución.

\section{JUSTIFICACIÓN}

La inasistencia alimentaria es un problema que cada día viene creciendo en el país y que trae consecuencias en la violación de los derechos de los niños, en los derechos que establece la Constitución y mucho más grave las consecuencias psicológicas, emocionales, físicas y de salud que se traducen en violencia intrafamiliar.

Como estudio descriptivo se busca establecer las bases que alimentan la línea de investigación sobre violencia intrafamiliar que desarrolla la Facultad de Derecho y que permitan realizar investigaciones más avanzadas de tipo descriptivo, comparativo, de análisis y evaluativos a corto, mediano y largo plazo.

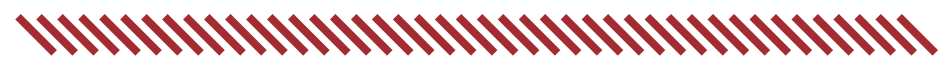




\section{AÑO 2007}

\section{DIAGNÓSTICO SITUACIONAL DE LOS DERE- CHOS DE LOS DESPLAZADOS EN LA CIUDAD DE VILLAVICENCIO}

\section{Codigo en Biblioteca UNIMETA}

342.085 R62d

\section{AUTORES}

Nelson Enrique Rodríguez Balaguera

Robert Ferley Gutiérrez Parrado

\section{RESUMEN}

El desplazamiento forzado es un problema político en su origen y en sus consecuencias, con traumáticas incidencias sociales, económicas, demográficas y culturales y como una manifestación critica de la violación de los derechos fundamentales de una población dispersa y fragmentada. Hasta finales del 2006, se acumularon 9.445 familias en situación de desplazamiento en la ciudad de Villavicencio.

Este estudio intenta responder a la siguiente pregunta: ¿Cuál es la situación actual de los desplazados en materia de los derechos humanos, en la ciudad de Villavicencio? Se utilizaron fuentes de información primaria (encuesta a través de entrevista a una muestra de 105 familias) y secundaria. Se estableció que la razón principal por la que las personas son obligadas a abandonar forzosamente su hogar son las amenazas $(27.2 \%)$ y el enfrentamiento armado (26.2\%), y los autores que motivaron el fenómeno de desplazamiento son: guerri1la $(47.3 \%)$, paramilitares $(33.1 \%)$ y ejército $(11.8 \%)$. Igualmente el $57.9 \%$ de los encuestados no conoce sus derechos como desplazado y un bajo porcentaje aplica los mecanismos constitucionales como el derecho de petición y el derecho de la tutela.

Una de las recomendaciones principales es la de generar un programa que auspicie un proceso de retorno pionero en el país. Esta situación es preocupante ya que del total de la población encuestada solo un $2 \%$ desea retornar. Igualmente se deben establecer proyectos de generación de ingresos que permitan disminuir el grado de vulnerabilidad de los hogares en situación de desplazamiento en aspectos como salud, educación y seguridad alimentaria.

\section{OBJETIVO GENERAL}

Describir el alcance reparador de los derechos de la población en situación de desplazamiento de la ciudad de Villavicencio y determinar el nivel de cumplimiento por parte del Estado.

\section{OBJETIVOS ESPECÍFICOS}

- Explorar el contexto histórico, teórico y legal del desplazamiento interno en Colombia.

- Describir la situación actual del desplazamiento interno en Colombia, el departamento del Meta y la ciudad de Villavicencio.

- Establecer a través de un estudio, la situación del desplazamiento en la ciudad de Villavicencio y el cumplimiento de sus derechos por parte del Estado.

\section{JUSTIFICACIÓN}

El desplazamiento es uno de los principales problemas que está viviendo la ciudad de Villavicencio, ocupando el séptimo puesto a nivel nacional. Se describe en qué grado a los desplazados de Villavicencio se les están violando sus derechos, respecto a los derechos civiles fundamentales, derecho a no ser discriminados por su condición social de desplazados, derecho a acceder a soluciones definitivas de su situación, derecho al regreso a su lugar de origen, derecho a no ser desplazados forzadamente, derecho a que su libertad de movimiento no sea sujeta a más restricciones que las previstas en la ley y el deber del Estado en propiciar las condiciones que faciliten la convivencia entre los colombianos, la equidad y la justicia social.

La caracterización social de la población desplazada es un punto de partida para comprender la dimensión de la problemática en el municipio de Villavicencio y poder realizar acciones de reparación y construcción de alternativas que ayuden a mitigar la situación de desplazamiento.

\section{ANÁLISIS Y EVALUACIÓN CRÍTICA DEL IMPACTO DE LA JURISDICCIÓN DE PAZ EN VILLAVICENCIO}

Codigo en Biblioteca UNIMETA

303.66 B17a

\section{AUTORES}

Leidy Lorena Barón Rojas

Jairo Hernando Acosta Roa

\section{RESUMEN}

El objetivo principal de este estudio es el de establecer los alcances y limitaciones de la Jurisdicción de Paz en 


\section{ISSN-2248-736 * Número 3 * Revista Facta Non Verba}

la ciudad de Villavicencio, el porqué de su aplicación tardía y el de su impacto en la ciudadanía. La muestra poblacional se dividió en dos grupos: A. El primero estuvo constituido por las autoridades que conforman la jurisdicción de paz (se aplicó una encuesta a 4 de los 11 Jueces de Paz electos, correspondientes a las comunas 2, 3,4 y 5 respectivamente, y a 2 Jueces de Reconsideración de los 14 electos pertenecientes a las comunas 7 y 8 respectivamente. B. El segundo grupo estuvo conformado por la ciudadanía en general (se seleccionaron de manera aleatoria 52 personas mayores de edad y con relaciones comerciales en la comuna).

Se estableció que la Jurisdicción de Paz a nivel local se encuentra en un estado embrionario e incipiente de desarrollo. La figura ha tenido una aplicación parcial y limitada, desvirtuándose el objeto último de la misma, como lo es la convivencia armónica entre ciudadanos. El desconocimiento de los mecanismos alternativos de solución de conflictos ha sido el común denominador que rige los esfuerzos dispersos de las partes involucradas.

También se estableció que los conflictos sociopolíticos de Villavicencio, el escaso margen de desarrollo cívico, la ausencia de lineamientos democráticos y la falta de educación, han sido factores que han menoscabado los grados de eficacia, eficiencia y diferenciación con otros operadores de justicia, esperados de la Jurisdicción de Paz. Igualmente, la capacitación recibida por los Jueces de Paz y de Reconciliación electos, se reporta como insuficiente en cuanto a la intensidad horaria y la continuidad en la realización de actividades tendientes a enriquecer el conocimiento, manejo y utilización de la Justicia de Paz.

\section{OBJETIVO GENERAL}

Identificar, determinar, evaluar los procesos y el impacto en la comunidad, de la aplicación de la institución de los Jueces de Paz y Reconsideración en el municipio de Villavicencio, mediante la encuesta y la entrevista como instrumentos de recolección de datos e información.

\section{OBJETIVOS ESPECÍFICOS}

- Examinar el contexto y contenido de lo preceptuado por el Art. 247 de la Constitución Política de Colombia y desarrollado en la Ley 497 de 1999.

- Identificar y clasificar los asuntos y aspectos fundamentales derivados de los contenidos de la Ley 497 de 1999 y explicarlos en sus alcances y limitaciones en la ciudad de Villavicencio.
- Analizar los procedimientos de capacitación y formación de los Jueces de Paz, su implementación y el impacto de la Justicia de Paz en Villavicencio.

- Aplicar instrumentos a una muestra de personas y jueces de paz electos en el municipio de Villavicencio, para identificar y determinar criterios que midan el impacto, eficacia y productividad de la puesta en marcha del nuevo procedimiento de solución de conflictos.

- Sistematizar y ordenar las explicaciones e interpretaciones resultantes de la lectura de los instrumentos aplicados en el proceso de investigación.

\section{JUSTIFICACIÓN}

El conjunto de situaciones concretas que se estudian, constituye un proceso reciente en el ordenamiento institucional de la justicia colombiana. Igualmente el tema investigado es de interés nacional y local, circunscrito al ámbito jurisdiccional especial, en donde los particulares (líderes comunitarios) son investidos para ejercer como Jueces de Paz, aplicando un criterio basado en la equidad, valores axiológicos y naturales, creándose gran expectativa en cuanto a los resultados esperados y su efectividad.

De la misma manera el tema genera confrontación con diversos enfoques, tendencias, corrientes e intereses que se dinamizan y que resultan de las posiciones específicas y particulares de los actores directos (la comunidad) e indirectos (la personería, la Jurisdicción Ordinaria y los gobernantes).

\section{PRESTACIÓN DE LOS SERVICIOS DE SALUD EN LA I.P.S. DEL BARRIO POPULAR VINCULADAA LA E.S.E. MUNICIPAL DE VILLAVICENCIO}

Codigo en Biblioteca UNIMETA

T362.1 P12p

\section{AUTORA}

Dalila Padilla Ramírez

\section{RESUMEN}

A lo largo de la presente tesis se hace una descripción de la prestación del servicio de salud en la I.P.S. del Barrio Popular vinculada a la E.S.E. municipal de Villavicencio. En este contexto se muestra cómo, a pesar de las deficiencias en la prestación del servicio a la salud, los pacientes no hacen las respectivas denuncias ante las 
autoridades competentes debido a que desconocen sus deberes y derechos. Por último, se muestra cómo, el problema de la prestación de servicio de salud a los habitantes del barrio no depende sólo de las pocas horas que se encuentra en funcionamiento el centro ( 8 horas diarias y 26 días a la semana) y del poco personal médico, sino también de la negligencia de algunos profesionales de la salud que se encuentran laborando en dicho lugar.

\section{OBJETIVO GENERAL}

Determinar la responsabilidad en la prestación del servicio de salud en la I.P.S. del Barrio Popular vinculada a la E.S.E. municipal de Villavicencio.

\section{OBJETIVOS ESPECÍFICOS}

- Enumerar las principales normas expedidas en Colombia a cerca de la prestación de servicios de salud y su responsabilidad.

- Realizar una reseña sobre la E.S.E. Municipal de la ciudad de Villavicencio.

- Señalar la forma de financiación y los recursos económicos de la E.S.E. Municipal de Villavicencio.

-Estableceratravésdelasestadísticasloscasosderesponsabilidad que han presentado en elCentro de Saluddel Barrio Popular, adscrito a la E.S.E Municipal de Villavicencio.

\section{JUSTIFICACIÓN}

A partir de la expedición de la ley 100 de 1993 por el cual se creó el Sistema de Seguridad Social Integral, la salud en Colombia tomó un rumbo diferente; 1) La población que cuenta con un empleo fijo está afiliada al Sistema Contributivo, en el cual una parte de los aportes son pagados por el empleado y lo demás lo gana el empleador, 2) La población sin capacidad de pago para cubrir el monto total de la cotización, se encuentra vinculada al régimen subsidiado y tiene derecho a recibir la atención que prestan las instituciones públicas y privadas que tengan contrato con el Estado. Éste régimen es eminentemente transitorio, y la normatividad los clasifica como vinculados.

En Colombia un alto porcentaje de la población se encuentra desempleada y no cuenta con los recursos necesarios para afiliarse al Régimen Contributivo, recurriendo a la afiliación en el Régimen Subsidiado, viéndose obligados a acudir a los centros de salud. La importancia de la presente tesina radica en conocer de quién es la responsabilidad de la prestación del servicio de salud en las I.P.S. vinculadas a la E.S.E. Municipal de la Ciudad de Villavicencio.

\section{AÑO 2008}

\section{FUNDAMENTOS JURÍDICOS A LA PROBLEMÁ- TICA DE LOS PACIENTES CON ENFERMEDADES CATASTRÓFICAS O TERMINALES EN EL DE- PARTAMENTO DEL META}

\section{Codigo en Biblioteca UNIMETA 362.175 V49f}

\section{AUTORES}

Diana Celene Vivas Páez

Norma Liliana Aguilera Sánchez

\section{RESUMEN}

En Colombia las EPS y ARS son objeto de acciones de tutela y derechos de petición por los afiliados afectados, ante la negativa de estas entidades en suministrar atención, exámenes, medicamentos y procedimientos para cumplir con el tratamiento de enfermedades catastróficas. Con el objeto de conocer cuáles son los principales problemas e inconvenientes que se les presentan a pacientes con enfermedades catastróficas en instituciones de salud del municipio de Villavicencio y alrededores, se aplicó una encuesta y/o entrevista informal a 30 pacientes afectados.

La mayoría de los pacientes encuestados está inconforme con los servicios que les ofrecen las entidades a las cuales están afiliados, ya sea del régimen contributivo o subsidiado, ya que cada vez que acuden a solicitar una autorización de servicios, ya sea para procedimientos o medicamentos, deben acudir a un derecho de petición o acción de tutela; estos procesos atrasan los tratamientos de forma continua.

Se crea un manual o folleto para que las entidades de salud lo tengan en cuenta para que les sea suministrado a este tipo de pacientes y ojalá con anterioridad a la autorización del servicio de acuerdo al cronograma de su tratamiento. De esta manera se evitaría tanto la disminución de la calidad de vida del paciente y la empresa promotora de salud estaría cumpliendo con sus requerimientos y obligaciones, teniendo en cuenta las nuevas disposiciones del gobierno donde se incluyen nuevos tratamientos, procedimientos y medicamentos de alto costo incluidos dentro del POS que no son objeto de acción de tutela.

\section{OBJETIVO GENERAL}

Reconocer la importancia que tiene la reglamentación jurídica del Estado Colombiano sobre el tratamiento dado a las enfermedades catastróficas y el cumplimiento suministrado por las entidades que tienen la obligación de dar protección y atención a la población afiliada $\mathrm{y}$ vinculada. 


\section{AÑO 2009}

- Investigar si las EPS y ARS están cumpliendo con lo dispuesto por la ley y siguen las normas establecidas para cada caso específico en el departamento del Meta. - Identificar los programas establecidos por el Ministerio de Protección Social para garantizar la atención integral de la lucha contra el VIH-SIDA.

- Analizar los planes y programas de promoción y prevención de enfermedades catastróficas así como el tratamiento para cada una de las enfermedades ruinosas o catastróficas, teniendo en cuenta la oportunidad en la entrega de sus medicamentos.

- Determinar los perjuicios, inconvenientes y métodos a los cuales tienen que acudir los pacientes con enfermedades catastróficas para acceder a una atención o tratamiento requerido según su patología.

- Establecer la génesis del concepto de la enfermedad catastrófica a partir de la jurisprudencia de la Corte Constitucional.

\section{JUSTIFICACIÓN}

Las enfermedades catastróficas son aquellas que pueden ser causadas por diferentes patologías, adquiridas o congénitas, se dice que son catastróficas debido a que además de ser costosas son enfermedades terminales. El Estado y el Sistema General de Seguridad Social garantizarán el suministro de los medicamentos, reactivos y dispositivos médicos autorizados, para el diagnóstico y tratamiento de las enfermedades ruinosas o catastróficas, de acuerdo con las competencias y las normas que deben atender cada uno de ellos.

En este trabajo se investiga y analiza si se está cumpliendo con lo dispuesto en las leyes que se reglamentan para el cumplimiento en lo que respecta a la salud de los colombianos como son las siguientes: Acuerdo 72 y 74 de 1997, Resolución 5261 de 1994, Ley 100 de 1993, Acuerdo 228 de 2002, Medicamentos no POS, Ley 972 de 2005, Resolución 4288 de 1996, entre otras.

WIIIIIIIIIIIIIIIIIIIIIIIIIIIIIIIII

\author{
Facta Non Verba
}

Revista

\section{DIAGNÓSTICO DE LAAPLICACIÓN DE LA LEGISLACIÓN DE AGUAS FRENTE A LA GESTIÓN DE LA EAAB PARA EL AÑO 2008}

Codigo en Biblioteca UNIMETA

T344. 0646343 S16d

\section{AUTORES}

Claudia Pastora Sánchez Sierra

Lennys Johanna Santiago Pinzón

\section{RESUMEN}

A lo largo de la presente tesis se demuestra cómo, durante la gestión del AÑO 2008, la Empresa de Acueducto y Alcantarillado de Villavicencio, tuvo en cuenta toda la normatividad de aguas emanada por los diferentes estamentos procurando darle estricto cumplimiento a la Constitución y a las normas que rigen y vigilan a los prestadores de servicios públicos.

\section{OBJETIVO GENERAL}

Demostrar si en la gestión del año 2008, la empresa de acueducto y alcantarillado de Villavicencio, ha prestado un servicio óptimo, eficiente y amplio a los suscriptores de esta empresa, dando cumplimiento a la normatividad existente.

\section{OBJETIVOS ESPECÍFICOS}

- Demostrar si el agua suministrada por la Empresa de Acueducto y alcantarillado de Villavicencio es potable y/o apta para el consumo humano.

- Determinar si las coberturas señaladas por la ley son cumplidas por la empresa prestadora de servicio público. - Demostrar si la empresa prestadora de servicios públicos cumple con las disposiciones de manejo del medio ambiente, emanadas por las autoridades.

- Analizar si la empresa ha sido requerida o sancionada por los entes reguladores.

\section{JUSTIFICACIÓN}

La comunidad Villavicense tiene derecho a conocer si la empresa de Acueducto y Alcantarillado de Villavicencio, está cumpliendo con su objeto, misión y visión, como Empresa Prestadora de Servicios Públicos y prioriza el suministro de agua potable. 


\section{SITUACIÓN DE LOS DESPLAZADOS Y SUS DERECHOS FUNDAMENTALES CASO VILLAVICENCIO}

Codigo en Biblioteca UNIMETA 323.448 Q82s

\section{AUTORES}

Carlos Augusto Quevedo Robles

Fernando Urrego Lozano

\section{RESUMEN}

A lo largo de la presente tesis se hace una caracterización de la población desplazada de la ciudad de Villavicencio, la cual, según el DANE es de 384.000 , lo cual hace que el presupuesto de la ciudad sea corto con relación a la magnitud de la problemática. También se hace una descripción de los derechos que se ven vulnerados por causa de dicha situación y se muestra cómo, a pesar de la normatividad tendiente a fortalecer los mecanismos de atención a los desplazados, no existe aún en Villavicencio una política definida, pues ni siquiera se ha iniciado la implementación del plan Integral Único de Atención al Desplazado, lo que se ve agravado por el desconocimiento de los funcionarios con respecto al tema y la falta de trabajo armónico entre las entidades encargadas del tema. Por último, la tesis muestra que en el municipio de Villavicencio no existe una política de tierras que permita el retorno o reubicación de los desplazados en condiciones dignas y garantías de seguridad para que los hechos acaecidos con ellos no se repitan.

\section{OBJETIVO GENERAL}

Determinar si las autoridades públicas del municipio de Villavicencio, tienen políticas públicas adecuadas que cumplan con el goce efectivo de los derechos de la población en situación de desplazamiento que señaló la Corte Constitucional.

\section{OBJETIVOS ESPECÍFICOS}

-Establecer la distancia entre los programas de la Alcaldía de Villavicencio, la Gobernación del Meta y los postulados expuestos en la Sentencia T-025 de 2004 de la Corte Constitucional.

-Identificarcuálessonlosderechosfundamentalesalosque no tiene acceso la población desplazada en mayor grado. - Formular herramientas teóricas para que la población desplazada identifique cuáles son los derechos que no se le están cumpliendo, de acuerdo con las necesidades que presentan.

- Socializar entre la población desplazada las herramientas jurídicas que la benefician y a través de éstas se impidan la violación de sus derechos fundamentales.

\section{JUSTIFICACIÓN}

La investigación sobre la situación de los desplazados y sus derechos fundamentales caso Villavicencio, surge como una necesidad sentida por parte de los autores que buscan a través de ella beneficiar a la población desplazada del Municipio, para conocer si están recibiendo la atención adecuada en los diferentes programas que se adelantan por parte de los entes del Estado y si se cuenta con los recursos necesarios para hacerlo. Este trabajo busca demostrar a los entes territoriales que no están cumpliendo con eficiencia la atención a desplazados, por ello al final del documento se dan a conocer las recomendaciones necesarias, para que el Estado entre a tomar los correctivos.

\section{EVOLUCIÓN ADMINISTRATIVA Y TERRITORIAL DEL DEPARTAMENTO DEL META DESDE EL DESCUBRIMIENTO DE AMÉRICA HASTA NUESTROS DÍAS}

\author{
Codigo en Biblioteca UNIMETA \\ T 343.04 A77e
}

\section{AUTORES}

Jennifer Carolina Aroca Campo

Carlos Javier Zuluaga Vargas

\section{RESUMEN}

A lo largo del presente trabajo se describe brevemente la evolución del territorio del departamento y se señalan las diferentes etapas delimitadas por el ordenamiento normativo constitucional y legal vigente en Colombia durante cada una de las etapas históricas; además, se aborda el caso específico del departamento del Meta y se proyecta los posibles derroteros que se vislumbran en este capo, según los postulados contemplados en la constitución vigente para la organización territorial del Estado Colombiano. 


\section{OBJETIVO GENERAL}

Establecer, y analizar la evolución de la Estructura administrativa-territorial del Departamento del Meta con el fin de determinar la formación territorial del departamento y las instituciones administrativas de derecho público que lo han regido.

\section{OBJETIVOS ESPECÍFICOS}

- Identificar el proceso de evolución territorial y administrativa del departamento de Meta desde la constitución de 1886 hasta nuestros días.

- Analizar las diferentes instituciones que han sido ejecutoras de la administración pública en Colombia, aplicables al departamento del Meta, sus orígenes, su evolución y su estado actual.

- Identificar, la normatividad que ha regulado la organización territorial y administrativa del Departamento del Meta desde 1886 hasta la actualidad.

- Caracterizar el estado actual del desarrollo administrativo territorial del Departamento y visualizar las proyecciones que en esa materia se vislumbran a partir de la constitución de 1991 y la legislación vigente.

\section{JUSTIFICACIÓN}

Constante ha sido el esfuerzo y la necesidad de estudiar la administración pública en Colombia, bajo varios aspectos y en diversos campos. Pero su evolución desde el descubrimiento del territorio colombiano, los diferentes momentos de su desenvolvimiento, las normas constitucionales y legales que dieron vida al andamiaje de la administración pública, todo para fundamentar y tener una comprensión amplia y suficiente de las actuales modalidades de administración pública, a nivel nacional y regional, y su influencia en el cotidiano vivir de la comunidad, todo enfocado desde el punto de vista territorial.

Para el caso del departamento es más que pertinente en la medida que es escaso por no decir que nulo, la existencia de material que aborde la normatividad que ha regido en el ámbito administrativo y territorial del departamento del Meta.

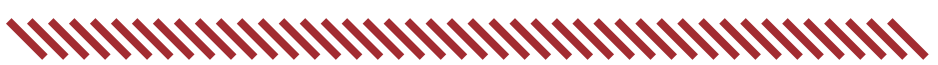

\author{
Facta Non Verba \\ Revista
}

\section{EVOLUCIÓN ANTITERRORISTA EN COLOMBIA A PARTIR DE LA CONSTITUCIÓN DE 1991 Y SU APLICACIÓN AL CASO DEL 7 DE ABRIL DE 2002 Y AL 6 DE MARZO DE 2009}

\author{
Codigo en Biblioteca UNIMETA \\ $\mathrm{T} 345.02 \mathrm{~V} 25 \mathrm{e}$
}

\section{RESUMEN}

En Colombia el terrorismo es el método que han elegido los grupos armados ilegales para atentar contra la estabilidad del Estado. Como resultado de sus actos criminales, mediante el uso de armas no convencionales y de atentados premeditados, esas organizaciones han convertido a los civiles en su blanco principal. Se discute si el terrorismo es un factor de desestabilización de la institucionalidad jurídica, política, social y económica del Estado. Igualmente se establece si en el caso concreto de los atentados terroristas del 7 de abril de 2002 y el 6 de marzo de 2009 en Villavicencio, se han implementado medidas estatales tendientes a la indemnización de las víctimas. Se utilizaron fuentes de información secundaria y primaria, esta última suministrada por funcionarios de la Unidad de Derechos Humanos de la Fiscalía General de la Nación, Seccional Villavicencio y la Dirección Técnica de la Empresa de Acueducto y Alcantarillado de Villavicencio.

Se demuestra que el problema del terrorismo, más que un problema legislativo, es un flagelo social, económico y político, que afecta a todas las clases sociales. A pesar de las iniciativas y clamores populares, el legislativo no ha asumido posturas serias y responsables frente al tema del terrorismo, y su desarrollo ha sido tenue y a veces insuficiente para los avances del terrorismo. En cuanto a las víctimas de los dos atentados ocurridos en Villavicencio, como fueron población civil, no fueron reparados de la manera debida, creando descontento y desconfianza en las instituciones estatales por parte de las víctimas.

\section{OBJETIVO GENERAL}

Demostrar si con la legislación actual en contra del terrorismo se puede contrarrestar este problema y mitigar los efectos producidos a los afectados directos y a la comunidad villavicense en general y si es una respuesta eficaz al clamor ciudadano que lucha contra este flagelo. 


\section{OBJETIVOS ESPECÍFICOS}

- Determinar si ha existido un compromiso serio y responsable del legislativo sobre el tema.

- Valorar si la legislación en contra del terrorismo ha tenido un desarrollo satisfactorio, cumpliendo su cometido.

- Analizar si se ha estado enfrentando el problema del terrorismo con la legislación adecuada.

- Determinar si los afectados con el atentado terrorista del 7 de abril de 2002 y el 6 de marzo de 2009 han recibido la ayuda oportuna y eficaz.

\section{JUSTIFICACIÓN}

Como ciudadano y estudiante de derecho se debe tener conocimiento del desarrollo legislativo que se ha tenido frente al terrorismo a partir de la constitución de 1991 y las medidas diseñadas para la sociedad víctima de este, así como los mecanismos jurídicos que se tienen como ciudadano para reclamar los perjuicios ocasionados por el terrorismo.

\section{AÑO 2010}

\section{ANÁLISIS SOBRE LA APLICACIÓN Y RESULTADOS DE LA LEY 1122 DE ENERO 9 DEL 2007 HASTA EL 31 DE DICIEMBRE DEL 2008 EN VILLAVICENCIO - META POR MEDIO DE LA CUAL SE REFORMO EL SISTEMA GENERAL DE SEGURIDAD SOCIAL EN SALUD.}

Codigo en Biblioteca UNIMETA

344.02 A94A

\section{AUTORES}

Germán Eduardo Ávila Rodríguez

Dagoberto Carvajal Pineda

\section{RESUMEN}

Este estudio busca dar respuesta al siguiente interrogante. ¿Cuál ha sido el incremento en la cobertura en salud registrado por las EPS, a partir de la aplicación de la Ley 1122 del 2007 hasta el 31 de diciembre del 2008 en la ciudad de Villavicencio? Se seleccionó una muestra de 100 personas a quienes se les aplicó una encuesta en el momento que asistían a las diferentes EPS de la ciudad, con el fin de identificar su aceptación hacia los servicios que se les prestan.

El 57\% de los encuestados manifestó que no ha mejorado la calidad del servicio con la Ley 1122 del 2007 y el $87 \%$ no conocen los beneficios de la misma. SaludCoop es la EPS con el mayor número de afiliados en la ciudad; el $68 \%$ de los encuestados están conformes con la atención en esta entidad. E1 85\% de los encuestados manifiestan no haber recibido capacitación en programas de Promoción y Prevención por parte de las EPS.

Para alcanzar la meta de cobertura del régimen subsidiado, se debe conocer realmente el total de la población objeto; de esta manera se podrá establecer la línea de base y superar la meta para llegar al cubrimiento universal. Se recomienda realizar una encuesta que permita conocer la calidad de vida, proyectar una mejor cobertura en aseguramiento que permita ampliar los programas, particularmente los de Promoción y Prevención, e ir ampliando el POS subsidiado.

\section{OBJETIVO GENERAL}

Analizar los posibles adelantos que se han tenido con la aplicación de la Ley 1122 desde el 7 de enero del 2007 hasta el 31 de diciembre del 2008, en el Sistema General de Seguridad Social en Salud, en cuanto al incremento de cobertura en salud en la población de la ciudad de Villavicencio con el fin de establecer si se logrará alcanzar el cubrimiento universal para los niveles uno, dos y tres para el 2011.

\section{OBJETIVOS ESPECÍFICOS}

- Determinar los antecedentes en cuanto a prestación de servicios de salud en Colombia y la normatividad existente hasta llegar a la Ley 100 de 1993 que organiza el Sistema General de Seguridad Social Integral.

- Conocer la Ley 1122 del 2007 para poder establecer las modificaciones que se hicieron al Sistema General de Seguridad Social en Salud, compararla con la Ley 100 de 1993 y establecer los avances y deficiencias que presenta. - Identificar la aceptación que existe en Villavicencio hacia los servicios que prestan las EPS, mediante la aplicación de encuestas a usuarios.

\section{JUSTIFICACIÓN}

Son muchas las inconsistencias en la prestación de los servicios de salud a los usuarios por parte de las EPS. Es así como se busca analizar si con la aplicación de la Ley 1122 del 2007 se está logrando su objetivo principal cual es el de lograr un eficaz mejoramiento en la prestación del servicio a los beneficiarios del Sistema General de Seguridad Social en Salud; en este cometido en caso de encontrar falencias se darán a conocer a las diferentes EPS de Villavicencio con el objeto de ofrecer los medios para que puedan alcanzar un cubrimiento universal en salud para el año 2011 en los niveles uno, dos y tres. 


\section{IMPACTO DEL SISTEMA PENAL ACUSATORIO EN LA INCIDENCIA DEL HOMICIDIO EN VILLAVICENCIO}

Codigo en Biblioteca UNIMETA 345 C266

\section{AUTORES}

María Isabel Cendales Tafur

Danna Kirssy Ramírez Benavides

\section{RESUMEN}

En Villavicencio se han dado todos los fenómenos sociales, políticos y económicos que favorecen la violencia. En los últimos 10 años la tasa de homicidios ha oscilado en el rango de 37- 116 casos por cien mil habitantes. En este estudio se compara el comportamiento de los índices de homicidio en Villavicencio durante el periodo $2004-2010$ y se determina si en esta ciudad se han tenido o no resultados favorables con el Sistema Penal Acusatorio, en relación con la reducción del homicidio y la desactivación de los agentes y factores que lo generan.

Se establece que el homicidio en Villavicencio tiene un comportamiento ligeramente superior al nacional: $75 \%$ de ellos son ejecutados con armas de fuego; el $82 \%$ carecen de información sobre las circunstancias del hecho; el 80.9\% carecen de información sobre el presunto agresor y la proporción de las víctimas es de una mujer por cada siete hombres. Se estima que la impunidad en el delito de homicidio es del 97\% y que el Sistema Penal Acusatorio no ha tenido efecto alguno en la reducción del homicidio. Entre otros, se recomienda diseñar y aplicar un plan integral de seguridad ciudadana, de estrategias efectivas para restablecer los valores y modelos de autocontrol social, de la tolerancia a la divergencia y respeto a la vida; de reducir la exclusión económica y la marginalidad social; de rediseñar la actitud y operatividad de la fuerza pública; de replantear y fortalecer el sistema penal; de rediseñar las políticas educativas y de fortalecer la cohesión familiar.

\section{OBJETIVO GENERAL}

Interpretar desde una perspectiva sociológica las cifras sobre la incidencia del homicidio en Villavicencio durante el periodo 2004 a 2010.

\section{OBJETIVOS ESPECÍFICOS}

- Interpretar desde una perspectiva sociológica e identificar los agentes y factores generadores del delito de homicidio en Villavicencio durante el periodo descrito. - Evaluar el impacto del Sistema Penal Acusatorio en la prevalencia del homicidio en Villavicencio.

\section{JUSTIFICACIÓN}

En Villavicencio se encuentran variadas interpretaciones sobre la incidencia del homicidio y su relación con los agentes y factores generadores del delito, pero la bibliografía es escasa en cuanto a su relación con el Sistema Penal Acusatorio. En esta tesis se analiza el homicidio desde el año 2004 hasta el 31 de mayo de 2010, tomando como base los reportes del Instituto Nacional de Medicina Legal y Ciencias Forenses. Igualmente y con el mismo propósito se utilizan las cifras que emiten la Policía Nacional y la Secretaria de Gobierno Municipal.

La información es diversa y en algunos casos contradictoria en razón al tratamiento o sesgo que cada uno le da, algunas veces alterando la realidad en cuanto a la casuística con el fin de mostrar resultados favorables frente a la lucha contra el delito. Hay diferentes agentes y circunstancias de tipo económico y social que han incidido en el comportamiento del homicidio en Villavicencio, como la marginalidad socioeconómica, la pobreza y la falta de oportunidades productiva en los sectores inferiores de la escala social y su convivencia con la delincuencia común y organizaciones armadas al margen de la ley y el narcotráfico.

\section{AÑO 2011 \\ ESTUDIO SOBRE LA VULNERACIÓN DE LOS DERECHOS EN LA POBLACIÓN DISCAPACITA- DA EN VILLAVICENCIO (META)}

\section{Codigo en Biblioteca UNIMETA}

323 C67E

\section{AUTORES}

Correa Reyes Edgar Iván

Figueredo Rigoberto

\section{RESUMEN}

Se establecen los derechos que le son vulnerados con mayor frecuencia a la población de Villavicencio en situación de discapacidad, por parte de los entes del Estado 
que deben preocuparse por su protección, aplicación y cumplimiento. Se aplicaron 93 encuestas a personas con alguna discapacidad y se confrontó la información obtenida con los programas que realiza la Alcaldía de Villavicencio y la Gobernación del Meta para el beneficio de la población discapacitada.

Se concluye que los derechos más vulnerados son el derecho a la movilidad y a la recreación con un $91 \%$, seguido del derecho a la cultura con el $89 \%$; con un $88 \%$ están el derecho al deporte y a una vida digna; con un $87 \%$ aparece el derecho al trabajo, seguido del derecho a la educación y por último el derecho a la salud con el $48 \%$. Se recomienda la inclusión del grupo familiar en los programas estatales, gestionar ayudas nacionales e internacionales, fortalecer las asociaciones y crear nuevas, la ampliación de la cobertura y atención integral, propender por la inclusión social y la no discriminación, aplicar el diseño universal en todos los lugares de acceso público, esto es, que se construyan ramplas y se instalen señalizaciones en Braille e íconos o figuras universalmente reconocidos, erradicar el analfabetismo y facilitar el acceso a la información, vincular la empresa privada e implementar el modelo de la diversidad.

\section{OBJETIVO GENERAL}

Conocer los derechos que le son vulnerados a la población en situación de discapacidad en Villavicencio (Meta) con el fin de socializar entre las personas discapacitadas de la ciudad el catálogo de sus derechos.

\section{OBJETIVOS ESPECÍFICOS}

- Obtener información directamente de la población en situación de discapacidad en Villavicencio, para conocer los derechos que le son vulnerados con mayor frecuencia por los entes estatales encargados de su protección, aplicación y cumplimiento.

- Identificar los programas que tiene la Alcaldía de Villavicencio y la Gobernación del Meta; la población que es atendida y su satisfacción en cuanto al trato que reciben. - Recopilar y socializar información sobre la normatividad que protege en Colombia los derechos de la población en situación de discapacidad, los beneficios que les trae y la forma como pueden acceder a ellos.

\section{JUSTIFICACIÓN}

En Colombia el porcentaje de personas en situación de discapacidad se estima que asciende al $6.5 \%$ de la población; por lo general son personas que no gozan de la igualdad de oportunidades laborales o educativas ya que son discriminados, en la mayoría de los casos por sus limitantes físicos. En Villavicencio no se han realizado estudios que permitan conocer las necesidades reales de la población discapacitada. Es importante conocer directamente de la población en discapacidad de Villavicencio, los derechos que consideran en mayor frecuencia vulnerados por los entes del Estado encargados de su protección, aplicación y cumplimiento. La confrontación de esta información con la de los programas que realizan la Alcaldía y la Gobernación son útiles para la implementación de programas dirigidos a la atención de las necesidades propias de los discapacitados y de sus familias, que los hagan sentirse valiosos para la sociedad.

\section{ESCUELA DE INGENIERÍAS Y ARQUITECTURA}

\section{PROGRAMA DE INGENIERÍA AMBIENTAL}

\section{AÑO 2009}

DISEÑO DE UN SISTEMA DE GESTIÓN AMBIENTAL PARA EL BARRIO PLAYA RICA EN LA CIUDAD DE VILLAVICENCIO

\section{Codigo en Biblioteca UNIMETA}

T 363.7 M86D

\section{AUTOR}

Kevin Ricardo Muñoz Bahamón

\section{RESUMEN}

En Colombia miles de personas viven en extrema pobreza, asediadas por la enfermedad, el hambre, la sed, la indigencia y la marginación, siendo la subsistencia su forma de vida tal como es el caso de algunos habitantes de la comuna 8 y en específico los del barrio Playa Rica de la ciudad de Villavicencio.

\section{OBJETIVO GENERAL}

Diseñar un sistema de gestión ambiental para el acueducto comunitario del barrio Playa Rica Villavicencio Meta para mejorar la calidad del agua y presentación del servicio domiciliario.

\section{OBJETIVOS ESPECÍFICOS}

- Diagnosticar el sistema de captación tratamiento y distribución de agua en el acueducto comunitario del barrio 
ISSN-2248-736 * Número 3 * Revista Facta Non Verba

Playa Rica de Villavicencio (Meta).

-Diseñar estrategias pedagógicas para los habitantes de la comunidad de Playa Rica con el fin de conseguir un acueducto de manejo hídrico.

\section{JUSTIFICACIÓN}

Este trabajo con el diseño del sistema de gestión ambiental propone soluciones viables a la problemática que presenta actualmente el acueducto comunitario del barrio Playa Rica con el propósito de mejorar así la calidad de agua y la buena presentación del servicio domiciliario para la comunidad.

\section{FORMULACIÓN PLAN INTEGRAL DE RESIDUOS HOSPITALARIOS Y SIMILARES (GESTION INTERNA) DEL HOSPITAL MILITAR DEL ORIENTE DE APIAY META}

Codigo en Biblioteca UNIMETA

T3565.72 M28f

\section{AUTOR}

Nilsa Brigette Mesa Fontecha

\section{RESUMEN}

El presente trabajo de grado se llevó a cabo en el hospital militar de oriente HOMIO durante el segundo periodo del año 2008 y tuvo por objetivo proponer la formulación del plan de gestión integral de residuos hospitalarios y similares del hospital militar de oriente Apiay (Meta).

\section{OBJETIVO GENERAL}

Formular el plan de gestión integral de residuos hospitalarios y similares para el hospital de Apiay (Meta) como modelo de gestión de residuos en Colombia.

\section{OBJETIVOS ESPECÍFICOS}

- Elaborar un diagnóstico ambiental y sanitario general del manejo de los residuos hospitalarios y similares del Hospital Militar del Oriente.

- Realizar el análisis del diagnóstico ambiental y sanitario que permita evidenciar la problemática para gestionar su manejo.

\section{JUSTIFICACIÓN}

Actualmente son muchos los factores asociados a la contaminación ambiental. Entre estos se encuentran incluidos las instituciones prestadoras del servicio de salud, las cuales generan en el desarrollo de sus actividades una serie de residuos con características infecciosa, tóxicas, corrosivas, tales como combustibles las cuales se constituyen en factores de riesgo para la salud humana.

\section{ESTUDIO DE LA RELACIÓN DE PRACTICÁS AGRÍCOLAS CON LOS CAMBIOS POBLACIONALES MICROPOBLANOS DEL SUELO CONDICIONES DE CAMPO EN CULTIVOS DE ARROZ SECANO UBICADO EN LA VEREDA BELLA SUIZA - META}

\section{Codigo en Biblioteca UNIMETA}

T631.4 C67E

\section{AUTORES}

Lizeth Carolina Córdoba Garzón. Ingry Johanna Sánchez Sánchez.

\section{RESUMEN}

La presente investigación aborda el impacto ambiental sobre las biomasas microbiana del suelo por actividades agrícolas especialmente los compuestos xenobióticos o plaguicidas usados extendidamente en el control de malezas y plagas considerando condiciones de campo en un cultivo de arroz secano ubicado en el departamento del Meta Villavicencio en la vereda bella suiza.

\section{OBJETIVO GENERAL}

Evaluar la relación de las prácticas agrícolas en los cambios de poblaciones microbianas del suelo en el cultivo de arroz secano en condiciones de campo ubicado en la vereda Bella Suiza Meta.

\section{OBJETIVOS ESPECÍFICOS}

- Establecer cambios de densidad y diversidad microbiana durante el ciclo del cultivo de arroz secano.

- Analizar la influencia de la práctica agrícola utilizada en los cambios de densidad y diversidad microbiana.

- Evaluar el impacto ambiental de las alteraciones sobre las poblaciones microbianas del suelo.

\section{JUSTIFICACIÓN}

El impacto generado por las prácticas agrícolas sobre la micro biota del suelo no solo es un problema de productividad para el sector agrícola sino que nos concierne a todos como integrantes de un medio común pues este entrelaza los tres componentes ambientales agua suelo atmosfera. Su importancia ambiental se ha relegado dándole prioridad a los llamados microorganismos beneficios a costa del equilibrio ecológico. Estos microorganismos, llevan a cabo una enorme cantidad de reacciones sobre los elementos componentes de la vida. 


\section{AÑO 2010}

\section{IDENTIFICACIÓN DE OXIDASAS EN HONGOS DE DIFERENTES GRUPOS ECOLÓGICOS DE CAPACIDAD DE BIOREMEDIAR SUELOS CONTAMINADOS CON HIDROCARBUROS POLICÍCLICOS EN EL POZO NÚMERO DOS DE CASTILLA LA NUEVA DEPARTAMENTO DEL META}

Codigo en Biblioteca UNIMETA

6333.7 D13A

\section{AUTOR}

Daniel Enrique Mejía Cáceres.

\section{RESUMEN}

Los hongos posees un sistema enzimático oxidativo extracelular capaz de degradar compuestos orgánicos persistentes esta capacidad los permite ser utilizados de biorremediación de aguas y suelos contaminados, sin embargo, el uso de estos hongos requiere la determinación de condiciones adecuadas para aumentar su crecimiento.

\section{OBJETIVO GENERAL}

Identificar la actividad de las enzimas oxidadas extracelulares mediante el análisis de una gran cantidad de hongos asolados de suelos contaminados por hidrocarburos en el departamento del Meta y correlacionar estas con su capacidad biodegradadora.

\section{OBJETIVOS ESPECÍFICOS}

- Comprobar que tan difundida esta la capacidad de formar este tipo de enzimas oxidadas extracelulares al realizar screnning en hongos de diferentes grupos ecológicos.

- Identificar no solo oxidasas sino también peroxidasas enzimas necesarias para la degradación de xenobióticos.

\section{JUSTIFICACIÓN:}

La utilización de hongos y enzimas es factible en sitipos contaminados por hidrocarburos aromáticos policíclicos donde su estabilidad química y su disponibilidad son un problema de la recuperación de recursos naturales impactados con compuestos derivados del petróleo.

\section{ANÁLISIS DE NIVELES DE COLISTERASA COMO INDICADOR DE CONTAMINACIÓN AMBIENTAL POR PLAGUICIDAS EN EL CORREGIMIENTO NÚMERO CUATRO DE MUNICIPIO DE VILLAVICENCIO}

Codigo en Biblioteca UNIMETA 614.7 M66A

\section{AUTOR}

Carlos Andrés Monzón Portela.

\section{RESUMEN}

El estudio pretende evaluar el impacto que tiene el uso y manejo de plaguicidas en los habitantes de zonas aledañas a pistas de fumigación y cultivos del corregimiento número cuatro del municipio de Villavicencio. Se realizó el análisis de los niveles de coliesterasa en 103 muestras biológicas, tomadas con consentimiento en habitantes de las veredas que componen el corregimiento, en igual número se atendió una encuesta como complemento de la investigación.

OBJETIVO GENERAL

Analizar los niveles de coliesterasa como indicador de contaminación ambiental por plaguicidas en el corregimiento número cuatro del municipio de Villavicencio con el fin de generar herramientas que fortalezcan las actividades de control y vigilancia que se realizan en la unidad de saneamiento ambiental.

\section{OBJETIVOS ESPECÍFICOS}

- Determinar la relación entre los resultados de las muestras biológicas tomadas y algunos hábitos y costumbres de los pobladores del corregimiento

- Relacionar nexos de causalidad de valores de actividad de coliesterasa y sintomatología asociada a intoxicaciones por agroquímicos mediante la elaboración de una matriz de la causalidad.

\section{JUSTIFICACIÓN}

Dada la localización en que se encuentra el municipio de Villavicencio, su suelo hace parte de una de las actividades económicas más significativas como lo es la agricultura, por lo tanto la comercialización de plaguicidas tiene gran importancia. También es de mayor grado el impacto adverso del uso indiscriminado de los plaguicidas en la salud y el ambiente; actuando como indicador de contaminación en las personas la enzima colinesterasa presentándose en la inhibición de las poblaciones periféricas de las pistas de aspersión y zonas más cultivables donde hay mayor flujo de estas sustancias. 


\section{PROGRAMA INGENIERÍA INDUSTRIAL}

AÑ̃ 2005

\section{ANÁLISIS ORGANIZACIONAL DE LA ENTIDAD PROMOTOR DE SALUD ETNOFUTURO S.A}

\section{Codigo en Biblioteca UNIMETA}

$658.1 \mathrm{C} 16 \mathrm{a}$

\section{AUTOR}

\section{Herbert Johan Cano Perea}

\section{RESUMEN}

El análisis organizacional creciente en el enfoque de los procesos y su diseño ha ido unido a una propuesta de cambio, también en la forma de gestionar las actividades de una organización. Tal como lo explica juran, el taylorismo introducido a principios del siglo XX impulso el avance de las industrias con una separación revolucionaria entre la planificación y la ejecución de procesos y sus actividades. Esta separación afecto también a la función de la calidad. Sin embargo, ya en la segunda mitad del siglo XX, las industrias japonesas descentralizaron la capacidad de gestionar la calidad, documentando las funciones y procedimientos logrando normalizar y estandarizar procesos que permitan minimizar costos y elevar la productividad, teniendo en cuenta la asignación de funciones y responsabilidades del personal integrante de la organización.

\section{OBJETIVO GENERAL}

Diseñar el manual de funciones y procedimientos de acuerdo a la estructura organizacional en la Entidad Promotora de Salud ETNOFUTURO S.A.

\section{OBJETIVOS ESPECÍFICOS}

- Teniendo en cuenta como fin el desarrollo del manual de funciones y procedimientos para cada una de las dependencias de E.P.S. ETNOFUTURO S.A, está orientado al logro eficiente de sus actividades, fundamentalmente en los siguientes objetivos.

- Definir estándares más efectivos basados en procedimientos homogéneos y metódicos; velando porque todas las actividades, acciones y recursos de La Entidad promotora de Salud EPS.
ETNOFUTURO S.A, interactúen en función del cumplimiento de la misión y objetivo institucional.

- Establecer responsabilidades en los puestos de trabajo dentro de la estructura organizacional, llevando a cabo un desempeño caracterizado por el mayor control de las actividades y autonomía de decisión en sus componentes organizacionales e independencia real de manejo del recurso humano para un mejor desenvolvimiento.

- Estandarizar procesos, aumentando la productividad al menor costo con el fin de minimizar tiempo en soluciones a situaciones, proponiendo la adecuada optimización de los recursos en la entidad; haciendo uso de tecnologías de punta para incrementar sus niveles de productivos; de igual forma que La Entidad Promotora de Salud EPS ETNOFUTURO S.A emprenda la ejecución en las actividades de proyección institucional, encaminadas al mejoramiento continuo.

- Permitir la evaluación del funcionario de manera objetiva, entre la asignación de responsabilidades según el manual y la forma como lo hace, describiendo las competencias básicas, intelectuales, básicas de comportamiento para los cargos establecidos en el desarrollo de las funciones de cada puesto de trabajo.

- Describir las diferentes características y requisitos de los cargos implicados en la dependencia de la entidad.

- Definir las funciones de los cargos en la entidad dentro del estudio general al realizar y presentarlas en formato adecuado.

- Soportar la correcta evaluación y seguimiento de la gestión organizacional, así como la confiabilidad de la gestión operativa y funcional.

- Canalizar el flujo de información simplificando funciones y procedimientos.

- Velar porque los sistemas y procedimientos tengan efectos cognitivos en los funcionarios en términos de posibilitar el mejor desarrollo de habilidades direccionales. - Proponer un instrumento práctico en el desarrollo de un proceso de calidad para lograr una eficacia en la realización de las actividades operacionales de la Entidad Promotora de Salud EPS ETNOFUTURO S.A buscando una política acorde con los lineamientos de la entidad.

\section{JUSTIFICACIÓN}

Los diferentes procesos organizacionales administrativos reflejan el pleno desarrollo y crecimiento de la empresa que deben estar enmarcados en la definición clara y precisa de todas y cada una de las funciones y procedimientos para llevar a cabo actividades con un alto nivel de desempeño. 
Es de esta manera que la Empresa Promotora de Salud ETNOFUTURO S.A en su afán de ser altamente competitiva , modernizar o actualizar su sistema administrativo con los lineamientos que se manejan en la actualidad no debe apartarse de adoptar todas las herramientas necesarias para buscar la uniformidad centralización y consolidación de los procedimientos desarrollados, por esta razón, se crea la necesidad de diseñar e implementar estos manuales, así mismo la estructura organizacional enmarcados en una viabilidad que ayuden al funcionamiento de la razón de ser de los cargos en las dependencia establecidas de acuerdo a esto obtener una mejor calidad de servicio de aseguramiento administrativo, brindando a toda la comunidad indígena y afiliados beneficios a corto, mediano, y largo plazo en cada uno de los niveles jerárquicos de la entidad encaminados en el mejoramiento continuo de los procesos.

\section{PLAN INTEGRAL DE MANEJO DE RESIDUOS SÓLIDOS RESIDENCIALES EN EL MUNICIPIO DE PARATEBUENO (CUNDINAMARCA)}

Codigo en Biblioteca UNIMETA

363.728R46p

\section{AUTORES}

Hernando Ríos Beltrán

William Albeiro Triana Cachaya

\section{RESUMEN}

Los residuos sólidos se han convertido en unas de las actividades más importantes en el mundo y los ingresos que estos generan por el mismo suponen una parte importante de la economía mundial. El departamento de Cundinamarca posee una alta oferta natural, soportada en paisaje , llanura, amaneceres, ríos, caños, lagunas, cascadas, esteros, morichales garceros, bosques de galería, piedemonte llanero, parques naturales, todo un conglomerado de oferta un tanto dispersa que requiere de una integración de componentes para formar un plan integral de manejo de los residuos sólidos residenciales que identifique a la región y la posiciones en un contexto nacional como conservado y preservadora del medio ambiente.

\section{OBJETIVO GENERAL}

Diseñar en Plan Integral de Manejo de Residuos Sólidos producidos en el sector residencial del municipio de Paratebueno (Cundinamarca), con el fin de mejorar la calidad de vida de sus habitantes.

\section{OBJETIVOS ESPECÍFICOS}

- Realizar un Plan alterno de manejo integral de residuos sólidos en el Municipio de Paratebueno (Cundinamarca). - Visitar e identificar cada uno de los principales recursos, material de desechos orgánico e inorgánico.

- Identificar en el Plan de Desarrollo del Municipio de Paratebueno (Cundinamarca) las estrategias o proyectos que permitan el desarrollo ambiental del municipio. - Diseñar una campaña y alternativas de solución que permitan una socialización para la aplicación del manejo adecuado del reciclado.

- Diseñar alternativas que permitan desarrollar proyectos propuestos en el plan de desarrollo para incentivar el sector ambiental del municipio de paratebueno y así preservar la fauna y flora del municipio.

- Realizar visitas a Empresas del sector público, privado y autoridades ambientales, con el fin de recopilar información e identificar los diferentes conceptos normas y parámetros a tener en cuenta en el manejo de los Residuos Sólidos Residenciales.

\section{JUSTIFICACIÓN}

La implementación de este proyecto es formular planes de procesos que proporcionen una solución a la problemática presentada en la recolección y selección de los residuos sólidos residenciales en este municipio. El cual general problema ambiental, en la salud y en algunos casos genera contaminación visual a los habitantes del sector residencial. Su disposición final se realiza en el botadero del municipio que en la actualidad se encuentra sellado por parte de autoridades ambientales como: Corporinoquia, La Umata, por no cumplir con los requisitos mínimos exigidos en estos casos. Cada municipio debe formular el "PGIRS" (Plan de Gestión Integral de Residuos Sólidos) el cual este se encarga de la selección, clasificación y manejo de procesos que ayudan al mejoramiento de la calidad de vida ambiental. El servicio de aseo presenta deficiencias en su recolección y transporte debido a que no cuenta con el equipo óptimo para realizar el proceso de recolección en el sector residencial.

IIIIIIIIIIIIIIIIIIIIIIIIIIII

$$
\begin{gathered}
\text { Facta Non Verba } \\
\text { Revista }
\end{gathered}
$$




\section{MODELO DE PROGRAMA DE SALUD OCUPACIONAL PARA EMPRESAS MOLINERAS}

Codigo en Biblioteca UNIMETA 613.62 Y $16 \mathrm{~m}$

\section{AUTORES}

Carlina Yánez Giraldo

Wilson Osvaldo Nieto Quevedo

\section{RESUMEN}

Una de las principales preocupaciones de una compañía debe ser el control de riesgos que atentan contra la salud de sus trabajadores y contra los recursos materiales y financieros.

Los accidentes de trabajo y enfermedades profesionales son factores que interfieren en el desarrollo normal de la actividad empresarial, incidiendo negativamente en su productividad y por consiguiente amenazando su solidez y permanencia en el mercado: conllevando además unas implicaciones en el ámbito laboral familiar y social.

\section{OBJETIVO GENERAL}

-Propender por el mejoramiento y mejoramiento de las condiciones de vida y salud de los trabajadores.

-Prevenir todo daño para la salud de las personas, derivado de las condiciones de trabajo.

-Controlar los agentes nocivos para la salud integral del trabajador en los lugares de trabajo.

-Proteger a los trabajadores y a la población contra los riesgos para la salud provenientes de la producción, almacenamiento, transporte, expendio y uso o disposición de sustancias para la salud pública.

\section{OBJETIVOS ESPECÍFICOS}

- Establecer el origen de los accidentes de trabajo y enfermedad profesional, realizando las actividades de prevención, promoción y protección para prevenir los riesgos, mejorar la salud y obtener una mejor calidad de vida. - Identificar las causas básicas que pueden producir daño a la propiedad, al proceso, al equipo, al producto. - Desarrollar actividades de vigilancia, inspección mantenimiento, control y protección de los bienes para aumentar beneficios y mejorar la eficiencia y productividad.

\section{JUSTIFICACIÓN}

El objetivo de este trabajo de investigación es brindar a las empresas molineras un modelo que les permita implementar con mayor facilidad su programa de salud ocupacional, debido a la inexistencia o no implementación de este en la mayoría de empresas con esta actividad.

Conclusión obtenida como resultado a la encuesta realizada a las empresas molineras que se encuentran en la base de datos de la cámara de comercio de Villavicencio.

La metodología está basada en la evaluación de los factores de riesgos según la norma NTC 045 a través de la observación directa a los factores de riesgos en las empresas y en los intercambios de información con las mismas.

\section{DISEÑO ADMINISTRATIVO PARA LA EMPRESA ANDIMA DEL LLANO DE LA CIUDAD DE VILLAVICENCIO}

\section{Codigo en Biblioteca UNIMETA}

$658 \mathrm{C} 18 \mathrm{~d}$

\section{AUTORES}

Yuliana Andrea Castro Ángel

Laura Carolina Rey Muñoz

\section{RESUMEN}

Las empresas pequeñas pueden funcionar con un diseño administrativo, una manera de orientar la adecuación de la organización en su entorno y unos procesos de crecimiento y expansión propios.

La división y jerarquización del trabajo en actividades y sub - actividades reconoce dimensiones críticas tales como: funciones y cumplimiento de aquellas acciones necesarias para la consecución de los objetivos operacionales planteados por la organización.

\section{OBJETIVO GENERAL}

Estructurar administrativamente la empresa ADNIMA DEL LLANO de la ciudad de Villavicencio, con el fin de incrementar la eficacia y lograr un buen sentido de pertenencia y principio de identidad hacia la organización. 


\section{OBJETIVOS ESPECÍFICOS}

- Establecer un diagnostico estratégico (interno y externo) de la empresa ANDIMA DEL LLANO con el fin de determinar las necesidades reales de mejoramiento.

- Definir un marco estratégico que permita establecer un rumbo claro hacia la efectividad administrativa.

- Establecer la estructura organizacional como herramienta fundamental dentro del proceso administrativo.

- Elaborar los manuales de funciones y procedimientos con el fin de lograr la estandarización de los procesos de la empresa.

\section{JUSTIFICACIÓN}

La empresa ANDIMA es una institución con ánimo de lucro , cuya actividad económica es la producción y distribución de empaques y embalajes administrada de manera empírica, en la cual se toman decisiones de acuerdo al comportamiento del mercado, la experiencia y la subjetividad del propietario, con poco sentido de pertenencia y compromiso del talento humano hacia la organización, impidiéndole mejorar la eficiencia de sus procesos y por ende ampliar su participación en el mercado regional y nacional.

\section{DISEÑO DE UN PROGRAMA PARA EL MANEJO DEL CUERO CRUDO DE BOVINOS}

Codigo en Biblioteca UNIMETA

646.1 R65d

\section{AUTORES}

Giovanni Romero Gaviria

Julián Andrés Barbosa Cúrvelo

\section{RESUMEN}

El Departamento del Meta por tradición histórica siempre se ha destacado en Colombia como una región agrícola y ganadera participe de la economía nacional. Esta participación no ha sido muy bien valorada desde el punto de vista económico retributivo hacia una mayor inversión, limitado el avance y el desarrollo del departamento.

La historia de la ganadería del departamento del Meta se vio perjudicada por la incursión de los grupos alzados en armas, que con sus prácticas de boleteo, saqueos y extorsiones, hicieron que gran parte de los ganaderos de la región se retiraran del sector, ocasionando escases en la inversión y de gestión por la economía ganadera; esta situación afortunadamente ha venido mejorando permitiendo así un resurgimiento en la economía ganadera.

\section{OBJETIVO GENERAL}

Diseñar un programa a nivel sanitario y normativo para el manejo del cuero crudo de bovinos que incluya, análisis de causas de defectos, diseño locativo y buenas prácticas de almacenamiento.

\section{OBJETIVOS ESPECÍFICOS}

- Elaborar un módulo de orientación dirigido a ganaderos en el manejo físico de las pieles de bovinos.

- Realizar el diseño locativo para optimizar el almacenamiento de cueros y así establecer un programa de inspección, seguimiento y control.

- Crear un módulo de orientación dirigido a frigoríficos en el manejo integral del cuero crudo de bovinos.

\section{JUSTIFICACIÓN}

Los frigoríficos en general demuestran poco interés por el aprovechamiento de los subproductos generados en su proceso principal (sacrificio de ganado) intentando invertir en capacitación para el manejo y control de esto, aún más, sabiendo que poseen una demanda significativa en cada uno de los diferentes mercados: tal es el caso de las pieles frescas o saladas de bovinos. Esta falta de interés hace que día a día los frigoríficos pierdan la oportunidad de incrementar sus ingresos además de convertirse en empresas más competitivas e integrales.

Además, la tendencia global está orientada a la implementación de modelos de gestión de la calidad, en donde uno de los focos vitales lo constituyen los proveedores, el sector del cuero que no es ajeno a esta situación, debe prepararse para que la producción de pieles crudas o saladas del departamento de Meta no queden excluidas, cumplimiento así las exigencias mínimas de espesor, marcas de herrajes, ralladuras, cortaduras y manchas ocasionadas por el tipo de sal utilizada en el proceso.

\section{DISEÑO E IMPLEMENTACIÓN BPM Y HACCP EN LA EMPRESA INVERSIONES LA CATIRA LTDA}

\section{Codigo en Biblioteca UNIMETA \\ 664 U71d}

\section{AUTOR}

Ayza Yamir Urbina Angarita

\section{RESUMEN}

La apertura comercial está acelerando los procesos de intercambiando de productos alimenticios entre diversos países.Portanto, asegurarelconsumodedichos productos 
ISSN-2248-736 * Número 3 * Revista Facta Non Verba

para que no sean nocivos para la salud humana se torna en un requisito para las empresas que desean tener acceso a los mercados nacionales e internacionales.

Como consecuencia de este cambio en el ambiente competitivo hoy las empresas requieren resolver de una vez por toda el problema de la inocuidad, la calidad de sus productos y la eficiencia de sus procesos productivos con el fin de enfocar sus esfuerzos en el desarrollo de estrategias de mercado que garanticen su consolidación y crecimiento y así competir con éxito logrando la calidad y productividad de las exigencias de un mercado globalizado.

\section{OBJETIVO GENERAL}

Diseñar e implementar las normas de aseguramiento de la calidad como son las buenas prácticas de manufactura y el análisis de peligros y puntos de control critico en la empresa inversiones La Catira LTDA.

\section{OBJETIVOS ESPECÍFICOS}

- Garantizar la inocuidad de los productos especialmente en la línea de quesos.

- Sensibilizar e involucrar al personal en la situación de buenas prácticas de manufactura B.P.M y análisis de peligros y puntos de control critico HACCP mediante talleres, capacitaciones y reuniones de grupos.

- Establecer un sistema de documentación donde existan procedimientos y registros apropiados para el funcionamiento de las buenas prácticas de manufactura B.P.M y análisis de peligros y puntos de control crítico HACCP. - Diseñar un plan de buenas prácticas de manufactura BPM y análisis de peligro y puntos de control crítico HACCP que prevengan los peligros de contaminación determinados por los parámetros higiénico sanitarios.

\section{JUSTIFICACIÓN}

En la actualidad el ambiente competitivo y las exigencias para alcanzar el mercado nacional e internacional de los productos, ha generado que las empresas colombianas implementen métodos de aseguramiento de la calidad que permita la eficiencia de sus procesos, alta calidad de sus productos y una rentabilidad económica estable. Por esta razón, la empresa inversiones la Catira Ltda. busca garantizar alimentos inocuos de alta seguridad satisfaciendo plenamente los requerimientos del cliente y a su vez cumpliendo con las normas vigentes establecidas por la legislación colombiana.

\section{CREACIÓN DE UNA EMPRESA PARA CONFECCIONAR Y COMERCIALIZAR PRENDAS DEPORTIVAS EN VILLAVICENCIO}

\author{
Codigo en Biblioteca UNIMETA \\ 646.2-L67c
}

AUTOR

\section{Blanca Lucia López Castaño}

\section{RESUMEN}

En vista de la actual situación por la que atraviesan las empresas de confecciones y siendo una actividad que se ha venido realizando de una manera muy artesanal y familiar, hemos optado por diseñar una empresa de confecciones para confeccionar y comercializar prendas deportivas en Villavicencio.

\section{OBJETIVO GENERAL}

Crear una empresa para confeccionar y comercializar prendas deportivas en Villavicencio con enfoque industrial en los procesos de producción como: Maquinaria, talento humano y métodos de trabajo aprobados al proceso de confección de calidad, lo cual se verá reflejadoenelmejoramientodelosreglonesdelaindustria.

\section{OBJETIVOS ESPECÍFICOS}

- Describir y analizar el nivel de demanda del mercado en el cual podrá desarrollarse la empresa de acuerdo a un estudio de mercados.

- Determinar el tipo de tecnología necesaria y la cantidad de maquinaria requerida, a partir de un estudio técnico del proyecto

- Organizar el proceso para la creación de la empresa de forma legal, gastos, ingresos y ganancia; de esa forma generar una mejor planificación.

- Plantear los procesos, métodos, operaciones críticas en la confección, responsabilidades y duración del trabajo. - Diseñar el manual de funciones para la empresa de confecciones la Orinoquía.

- Generar empleo en el área de las confecciones.

\section{JUSTIFICACIÓN}

El desarrollo de turismo, de pequeña industria y de comercio, para el futuro de la población de Villavicencio, gracias a la cercanía y paso obligatorio con la ciudad de Bogotá, Medina, Yopal, Puerto López, San Martin, etc. 
Se busca consolidar los sectores de industria y servicios, a través de la creación de microempresas, que es uno de los principios orientadores de la legislación frecuentemente adoptada en el país, así como también, tiendo presente las exigencias de calidad y precio a que se ven enfrentadas dentro del mercado competitivo.

\section{AÑO 2006 \\ DISEÑO, EVALUACIÓN TECNICA Y ECONÓMICA DE UNA PLANTA PARA PROCESAMIENTO DE PESCADO CULTIVADO EN EL MUNICIPIO DE CASTILLA LA NUEVA}

Codigo en Biblioteca UNIMETA

641.392 Q 84d

\section{AUTORES}

Alexander Quiroga Amado

Hernán Darío Mendoza Espitia

Jorge Rolando Tinjaca Holguín

\section{RESUMEN}

Con el transcurrir de los años la región de los Llanos Orientales, el Departamento del Meta y más específicamente en el municipio de Castilla la Nueva han experimentado una evolución en la industrialización del cultivo de especies exóticas (Tilapia Roja); y nativas (Yamu, Cachama Blanca-Negra y Bocachico), que ha elevado la producción de tal forma que presenta un alto índice de productividad a nivel departamental y nacional.

La piscicultura como actividad económica para el desarrollo de la región ha dado una gran importancia para fomentar e impulsar el empleo en las distintas regiones del país, originando interés para crear sistemas de producción a gran escala que generen apoyo económico para disminuir el desempleo a nivel nacional y regional.

\section{OBJETIVO GENERAL}

Diseñar una planta de procesamiento de pescado cultivado (tilapia roja y cachama) para el municipio de Castilla la Nueva con el fin de mejorar la calidad en el proceso de sacrificio y comercialización del producto.

\section{OBJETIVOS ESPECÍFICOS}

- Acopiar la información existente relacionada con el desarrollo del proyecto
- Identificar las debilidades y fortalezas del proyecto.

- Explicar los principales conceptos, enfoques y la importancia del proyecto.

- Analizar el estudio de mercado necesario para la utilización del proyecto.

- Diseño de planos para la macro-localización y microlocalización de la planta.

- Efectuar el estudio técnico adecuado para el diseño de la planta de procesamiento de pescado cultivado.

- Determinar la viabilidad económica para la implementación de la planta en el municipio de Castilla la Nueva. JUSTIFICACIÓN

La irregularidad del clima del Departamento del Meta (verano - invierno) durante el año hídrico hacen que la pesca del rio aumente en el periodo de aguas bajas (verano) y que escasee en el periodo de aguas altas (invierno). Lo anterior sumado a la falta de infraestructura adecuada para el procesamiento de pescado cultivado, ha hecho el estado colombiano a través de entidades como CORMACARENA el INPA hagan convenios con universitarios (Uniagraria, Unillanos) para el fomento y la asistencia técnica de la pesca en estanques de especies tales como la cachama, mojarra, bocachico, bagre entre otras especies.

A través del tiempo la producción de pescado del cultivo en el municipio de Castilla la Nueva ha venido aumentando. Esta producción surgió de las pequeñas empresas privadas, tal evento refleja la oferta para procesar la producción; unir estas empresas produce una considerable oferta de pescado en el departamento del Meta.

PROGRAMA INGENIERÍA CIVIL

\section{AÑO 2005}

\section{DÉFICIT DE VIVIENDA EN VILLAVICENCIO Y ESTUDIO DE UNA ALTERNATIVA ECONÓMICA UTILIZANDO ESTRUCTURAS CON PERFILES DE LÁMINA DELGADA}

Codigo en Biblioteca UNIMETA

624.1834 D41d

\section{AUTOR}

Javier Fernando Díaz Cely

\section{RESUMEN}

Esta tesina estudia y compara el sistema estructural tradicional de concreto reforzado con muros confinados, 
ISSN-2248-736 * Número 3 * Revista Facta Non Verba

con el nuevo de perfiles metálicos de lámina delgada, hace un estudio de déficit de vivienda cualitativo y cuantitativo en la ciudad de Villavicencio, explica las variables que inciden el costo de los principales insumos de la construcción (acero y cemento), hace referencia a la sismo -resistencia y a la amenaza de sismos en Villavicencio y estima los costos de la construcción de ambos sistemas estructurales con un análisis de precios unitarios.

\section{OBJETIVO GENERAL}

Identificar el problema de déficit de vivienda en el municipio de Villavicencio con base en las cifras oficiales del DANE y realizar una comparación de costos entre el sistema estructural tradicional y el de perfiles metálicos de lámina delgada con el fin de encontrar una mejor solución para combatir en déficit ofreciendo un mejor producto a un mejor precio y fomentar el uso de sistemas constructivos industrializados.

\section{OBJETIVOS ESPECÍFICOS}

- Elaborar un diagnóstico para el déficit de vivienda en Villavicencio con las cifras oficiales del DANE, analizando así la población objetivo (estrato 1,2 y 3 ) con el fin de identificar sus características y números de familias. - Describir y explicar las dos clases de déficit de vivienda para que la comunidad en general comprenda que abarca cada uno).

- Establecer las deficiencias del sistema estructural tradicional en capacidad sismo resistente, errores humanos en la construcción, eficiencia, y practicidad y analizar si estos se pueden mitigar con el sistema de perfiles metálicos. - Describir la amenaza sísmica de Villavicencio de acuerdo a estudios de microzonificación sísmica y explicar los conceptos básicos de la sismo resistencia.

\section{JUSTIFICACIÓN}

Se requiere la realización de este trabajo porque busca ayudar a la solución de uno de los más grandes problemas que tiene la sociedad villavicense. De no ser controlado el déficit vivienda se encontrarían las siguientes situaciones:

Incumplimiento del mandato constitucional que exige que cada colombiano tenga acceso a una vivienda digna así como tratados internacionales como la de la nueva declaración del milenio (New York, agosto 2000 ) en donde el gobierno se compromete a disminuir a la mitad este tipo de deficiencias.
La construcción ha demostrado ser el factor de la economía la crisis en este sector en el 1999 y el 2000 fue un factor determinado para tener una de las cifras más altas tasas de desempleo en el mundo.

El uso de tecnología de punta ha pasado de ser un lujo a una necesidad. No fomentar estos nuevos sistemas de construcción industrializados, traerá al país más atraso y lo dejara sin oportunidades de competir en los tratados de libre de comercio.

\section{MANUAL DE LINEAMIENTOS BÁSICOS PARA LA PLANEACION DEL TRANSITO EN LA CIUDAD DE VILLAVICENCIO}

\section{Codigo en Biblioteca UNIMETA \\ $338.41312 \mathrm{M} 60 \mathrm{~m}$}

\section{AUTORES}

Yenny Astrid Mosquera Novoa

Andrés Agustín Gutiérrez Penagos

\section{RESUMEN}

En la reestructuración y modificación del espacio urbano se debe recordar que este es un fenómeno social y cualquier cambio espacial urbanístico debe servir de puente frente al funcionamiento global de la ciudad y la operación particular de cada uno de sus elementos .Por esto al planificar las ciudades del siglo XXI se deben centrar los esfuerzos en mejorar las condiciones de vida de las ciudades intermedias dotándolas de infraestructura social, económica y política que coadyuven a mitigar la migración de la población hacia las grandes ciudades.

\section{OBJETIVO GENERAL}

Desarrollar un documento técnico que sirva de herramienta de planeación de tránsito para el municipio de Villavicencio; el cual, podrá ser usado por universidades entidades públicas o privadas entendidas en el tema para el desarrollo especifico de planeación de la ciudad y su infraestructura vial urbana de manera técnica , cumpliendo con las exigencias que tiene el estado a través del ministerio de transporte y el cual se denominará MANUAL DE LINEAMIENTOS SBASICOS PARA LA PLANEACION DEL TRANSITO EN LA CIUDAD DE VILLAVICENCIO. 


\section{OBJETIVOS ESPECÍFICOS}

-Evaluar las fuentes de información secundaria con que cuenta el municipio representada en estudios de tránsito y documentos de planeación como el plan de ordenamiento territorial.

- Generar la documentación a nivel del mapa temático de la zonificación propuesta para la matriz origen destino de la ciudad teniendo en cuenta la oferta vial que cuenta el municipio en la actualidad.

- Indicar las líneas de investigación adicionales que han de realizarse como complemento al inicio de esta investigación.

\section{JUSTIFICACIÓN}

La ciudad de Villavicencio sigue creciendo en la actualidad en diversos aspectos y el transito es uno de ellos, determinado por la ejecución de proyectos de gran escala como la nueva vía a Bogotá -Villavicencio y la intersección vial el Maizaro que brindan ventajas de movilidad y comodidad para sus usuarios.

\section{AÑO 2006 \\ ANÁLISIS DEL DETERIORO DEL PAVIMENTO EN LA CIUDAD DE VILLAVICENCIO, CASO: AVENIDA MARACOS}

Codigo en Biblioteca UNIMETA

625.86 P $12 \mathrm{a}$

\section{AUTORES}

Angélica Páez Moreno

Gina Constanza Lucumi Cantoñi

\section{RESUMEN}

Cualquiera que sea el tipo de pavimento existente se debe considerar los diversos factores que determinan las alteraciones sobre su estructura y afectan la seguridad comodidad con que circula el tránsito vehicular. Para el caso se desarrolla un análisis del deterioro del pavimento de la avenida maracos para conocer el estado actual de la estructura y así obtenida sus características físicas - mecánicas y deflexiones características poder postular una posible solución.

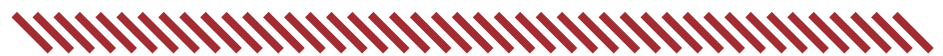

\section{OBJETIVO GENERAL}

Analizar el deterioro del pavimento de la Avenida Maracos en la ciudad de Villavicencio para conocer el estado actual de la estructura.

\section{OBJETIVOS ESPECÍFICOS}

- Recopilar la información sobre las variables necesarias para la realización del estudio como evaluación del pavimento, estudio de tránsito, estudio de materiales.

- Describir las características físico-mecánicas de los materiales constitutivos del pavimento a través de ensayos destructivos y no destructivos con el fin de conocer los daños estructurales.

- Confrontar los resultados obtenidos en campo y en laboratorios con las labores permisibles de esfuerzo y de formación según las normas en vías para la determinación y calificación del estado en la red vial, e internacionales con el fin de establecerse si se están cumpliendo las especificaciones técnicas.

- Realizar el inventario de fallas existentes en la vía para evaluar las características superficiales del pavimento.

- Sugerir una posible solución para el deterioro de los deterioros de los pavimentos.

\section{JUSTIFICACIÓN}

La infraestructura vial urbana ha venido creciendo a la par con el desarrollo de las ciudades convirtiéndose en el eje motriz para la realización de las diferentes actividades. Sin embargo, no se le ha dado la importancia que merece en cuanto a la planeación, por eso hoy en día las vías urbanas en nuestro medio son cada vez más caóticas desordenadas he ineficientes, porque algunos de sus componentes no están funcionando o lo hace de forma irregular ya sea en la infraestructura vial el vehículo y el usuario.

\section{PROGRAMA INGENIERÍA DE SISTEMAS}

\section{AÑO 2005}

ANÁLISIS Y DISEÑO DE UN SISTEMA DE INFORMACIÓN PARA EL MANEJO DE INVENTARIOS DEL ALMACEN LUBRICANTES ORINOCO DE PUERTO CARREÑO - VICHADA

Codigo en Biblioteca UNIMETA

005.74 M16a

\section{AUTORES}

Franklin Sneyder Mancera Mora

Patricia Peña Bustos

RESUMEN

Es importante recalcar que las empresas para poder 
ISSN-2248-736 * Número 3 * Revista Facta Non Verba

subsistir en el mercado, requieren obtener información de forma rápida, precisa y clara, para así poder obtener una ventaja competitiva frente a los demás. Es necesario incursionar en el desarrollo el software de alta calidad, capaz de responder a los requerimientos para poder manejar las organizaciones y entender cuál es el real impacto que tienen los sistemas informáticos frente al comportamiento de cualquier actividad económica.

\section{OBJETIVO GENERAL}

Analizar y diseñar un sistema de información para el manejo de inventarios del almacén lubricantes de Orinoco.

\section{OBJETIVOS ESPECÍFICOS}

- Recolectar información a través de técnicas como entrevistas, la observación, la investigación a los dueños empleados y clientes del almacén.

- Analizar la información suministrada por el almacén lubricantes Orinoco y las necesidades que el dueño quiere cubrir para determinar el diseño del programa.

- Establecer cuáles son los productos a sistematizar las entradas y salidas del almacén para poder codificarlas.

\section{JUSTIFICACIÓN}

La necesidad de estudiar la posibilidad de realizar un sistema de información que maneje automáticamente las funciones de registro y control de entrada y salida de productos y de información importante para el almacén para podertenertodalainformaciónalamanoordenadaencaso de alguna consulta de los clientes de una manera rápida.

\section{ANÁLISIS DE DISEÑO E IMPLEMENTACIÓN DE UN SISTEMA PARA EL SEGUIMIENTO DELICUENCIAL INDIVIDUAL DE LOS HABITANTES DE VILLAVICENCIO}

Codigo en Biblioteca UNIMETA

025.04 A51a

\section{AUTORES}

Antonio Mauricio Albarracín

Diana Milena Serrato Zamora

\section{RESUMEN}

El alto índice delincuencial que muestra cada día la ciudad de Villavicencio el cual es generado por diversos problemas ya sea de tipo social económico u otros, ha puesto de manifiesto urgente la aplicación de mayores controles por parte de la fuerza pública y demás organismos y direcciones del estado pero en mayor proporción de la policía nacional con sede en Villavicencio ya que por su función misma es quien debe garantizar la tranquilidad de sus habitantes.

\section{OBJETIVO GENERAL}

Diseñar y crear un software aplicado que le permita a la policía de Villavicencio, contar con una base de datos organizada actualizada y confiable que suministre todo tipo de información relacionada con las personas que estén involucradas en hechos contravenciones y directivos.

\section{OBJETIVOS ESPECÍFICOS}

- Determinar la viabilidad posibilidad y tipo de información que se permita conocer y trabajar para este sistema suministrada por la policía de Villavicencio.

- Establecer la forma y medios actuales de recolección y archivo de otro tipo de información (casos policiales) en las diferentes unidades policiales de Villavicencio.

- Establecer las falencias en el manejo de esta información llevando por los medios y técnicas actuales por el personal policial de cada unidad.

- Analizar esta información primaria (datos de los casos policiales y sus implicados) observando y manteniendo el marco legal de la misma.

\section{JUSTIFICACIÓN}

Teniendo en cuenta la estructura orgánica y laboral de la policía en Villavicencio dividida en unidades o grupos según su especialidad función lugar y horarios de servicios requiere con urgencia una base de datos que reciba y centralice toda la información posible tanto de personas vehículos personas y horarios tipos de hechos contravenciones y de hechos delictivos y de más elementos o características importantes de casos policiales que conoce al diario personal de la institución.

\section{SISTEMA DE INFORMACIÓN ADMINISTRATIVA BOVINA 'SIAB" DE LA EMPRESA "HACIENDA DE VENECIA}

\section{Codigo en Biblioteca UNIMETA \\ 005.74 T67m}

\section{AUTOR}

Pablo Emilio Torres Parra

\section{RESUMEN}

En este proyecto se propone una solución tecnológica para la propiedad Cabaña Venecia que consiste en un 
sistema informático que permita el control y registro y control de los bovinos de la propiedad asentados en la empresa ganadera.

\section{OBJETIVO GENERAL}

Desarrollar un sistema de información administrativa bovina SIAB para la propiedad ganadera cabaña Venecia.

\section{OBJETIVOS ESPECÍFICOS}

- Recopilar la información necesaria para el desarrollo del sistema.

- Aplicar la metodología del proceso unificado del desarrollo del software para el correcto desarrollo de la organización del sistema.

- Implementar el sistema en entorno visual BASIC.

- Implementar el sistema en la empresa cabaña Venecia y hacer sus pruebas correspondientes del sistema.

\section{JUSTIFICACIÓN}

El propósito de este proyecto es el de llevar a cabo una solución de tipo software a la empresa "Cabaña Venecia"; sobre el manejo y control de registro y reportes.

La implementación del proyecto es conveniente y trae como beneficio a la empresa "Cabaña Venecia", el de inhibir una falencia que se ha detectado en el manejo de registros y reportes, que se necesitan en momento dado. No sólo es beneficioso el proyecto para la empresa, si no también para las demás empresas del sector pecuario ganadero de Colombia y Sur América que quieran hacer uso del mismo.

AÑO 2006
ANÁLISIS, DISEÑO E IMPLEMENTACIÓN DE UN
SITIO WEB PARA LA EMPRESA SAXCLAR
MUSIC UBICADA EN LA CIUDAD DE
VILLAVICENCIO

Codigo en Biblioteca UNIMETA

004.692 P17a

\section{AUTOR}

Carlos Humberto Parrado Peñuela

RESUMEN

Latecnología esunmundoapasionantequeavanzaconpasosagigantadosyquien seresisteaellatiendea desaparecer.
Internet es uno de los miembros de esta tecnología siendo un mundo completamente complejo en el cual se pueden encontrar centenares de información de todo tipo .pero no solo brinda la posibilidad de encontrar esa información sino de también de tener un mundo en el cual la fronteras no existan.

\section{OBJETIVO GENERAL}

Analizar, diseñar e implementar un sitio web para la Empresa SAXCLAR MUSIC ubicada en la ciudad de Villavicencio para que sus clientes tengan una conexión directa con los productos y servicios que ofrece la empresa y así mismo poder ampliar los contactos con fabricantes y proveedores a nivel nacional.

\section{OBJETIVOS ESPECÍFICOS}

- Recopilar información teórica sobre la elaboración de un sitio web.

- Realizar un diagnóstico de la empresa SAXCLAR MUSIC.

- Elaborar la estructura de un sitio web que concuerde con las necesidades de la empresa SAXCLAR MUSIC.

- Establecer el portafolio de servicios de la empresa SAXCLAR MUSIC.

\section{JUSTIFICACIÓN}

Las distancias, las faltas del tiempo y sobre todo el limitado número de empresas dedicadas a la reparación y mantenimiento de instrumentos musicales luces y sonido profesional a nivel departamental han creado la necesidad en SAXCLAR MUSIC de buscar una opción para que sus clientes tengan una conexión directa con los productos y servicios que ofrece la empresa.

SISTEMATIZACIÓN DE FORMATO 040-021
DE EVALUACIÓN DE DOCENTES DELA
CORPORACIÓNUNIVERSITARIADELMETA VIA WEB
Codigo en Biblioteca UNIMETA
379.154S81s
AUTOR
Nidia Ximena Suárez Castro
RESUMEN

Se plantea una presentación del formato 040-021 de evaluación docentes de laCorporaciónUniversitaria del Meta vía web. Donde jalona como motor de edición de presentaciones y permite plantear el diseño gráfico óptimo para el 
ISSN-2248-736 * Número 3 * Revista Facta Non Verba

buen manejo de la planeación. Esta aplicación se desarrolla bajo software libre Linux pero no limita al usuario Windows.

\section{OBJETIVO GENERAL}

Sistematizar el proceso (formato del proceso 040-021) de evaluación docente de la Corporación Universitaria del Meta.

\section{OBJETIVOS ESPECÍFICOS}

- Recolectar información análoga en el ordenador con el fin de optimizar y mejorar el rendimiento de las aplicaciones según el usuario.

-Analizar la información depurada para crear herramientas que logren un buen desempeño en el nuevo diseño. - Diseñar un prototipo que permita evaluar la futura aplicación.

- Diseñar el software de evaluación docente para reducir errores imputables al procesamiento manual de la información.

\section{JUSTIFICACIÓN}

La presente investigación se realiza para poder aportar reflexiones teóricas y prácticas dentro de un contexto crítico sobre elementos esenciales del sistema acusatorio desde la perspectiva probatoria y la dinámica propia de las audiencias orales fundamento del sistema adversarial.

PROGRAMA INGENIERÍA AGROINDUSTRIAL

AÑO 2007

ESTUDIO DE RENTABILIDAD DE LA PLANTA AGROINDUSTRIAL EXTRACTORA DE ALMIDÓN Y HARINA DE YUCA CASO EN EL MUNICIPIO DE AGUAZUL - CASANARE

\subsection{G82e}

\section{AUTORES}

Gerardo Aly Guerrero Martinez

Wilmer Fernando Molano Acevedo

\section{RESUMEN}

En Colombia existen identificadas 396 plantas dedicadas al procesamiento de yuca ya sea para la obtención de harina o almidón o en efecto los dos productos las cuales solamente 241 registraron actividad por el 2005.
De las plantas que no presentaron actividad 74 estaban liquidadas, 70 inactivas y cerca del $50 \%$, 198, están concentradas en el Valle del Cauca y Cauca. Sus procesos son de forma semi - industrializada y en Casanare actualmente existen tres: Una ubicada en el municipio de Tauramena y otra en Paz de Ariporo, para las cuales sus procesos son semi-industrializados y se presenta una tercera que está localizada en el municipio de Aguazul la cual ES LA PLANTA PROCESADORA Y EXTRACTORA DE ALMIDON Y HARINA DE YUCA, donde sus procesos son $100 \%$ tecnificados y que representa para el departamento del Casanare una gran ventaja de desarrollo agroindustrial.

\section{OBJETIVO GENERAL}

Realizar un estudio de rentabilidad para la puesta en marcha de la planta agroindustrial extractora de almidón y harina de yuca ubicada en el municipio de aguazul Casanare.

\section{OBJETIVOS ESPECÍFICOS}

- Realizarundiagnósticode la condiciónactual de la planta para determinar cuáles son las causas para la inactividad. - Elaborar un inventario de la oferta de materia prima en los municipios de Villanueva, Monterrey, Tauramena, Maní, Aguazul y Yopal en el departamento del Casanare. - Realizarunestudiodemarcados parala plantaagroindustrialprocesadoraderaízdeyucadel municipiodeAguazul.

\section{JUSTIFICACIÓN}

La demanda mundial de alimentos es paralela al creciente aumento mundial de la población. Este último hecho ha conllevado a buscar nuevas alternativas para suplir estas necesidades, por esta razón se han adelantado investigaciones y estudios que nos ha permitido acercarnos a tan compleja problemática mundial como es el hambre que día a día se convierte en causas de conflictos y hasta de guerra entre los mismos seres humanos.

VIIIIIIIIIIIIIIIIIIIIIIIIIIIIIIIII

Facta Non Verba

Revista 


\section{AUTORES}

Ana Milena Rocha Osorio

Fabian Giovanny Wilches

\section{RESUMEN}

Los eslabones involucrados en la cadena del arroz son relativamente pocos en primer lugar se encuentran la producción agrícola del arroz la cual se cosecha en forma de arroz cascara verde en segundo lugar el procesamiento industrial el cual consiste en someter el arroz paddy a un proceso de secamiento el descascarillado el pulimiento para obtener un arroz blanco.

\section{OBJETIVO GENERAL}

Diseñar un sistema electrónico para el control autónomo constante y seguro de la temperatura por el horno quemador en cascarilla ubicado en los Molinos Roa S.A.

\section{OBJETIVOS ESPECÍFICOS}

- Ofrecer a la industria arrocera una nueva herramienta económica y eficaz para el proceso de arroz.

- Motivar a los estudiantes de la región para el desarrollo y la investigación de nuevas tecnologías.

\section{JUSTIFICACIÓN}

Ante los nuevos avances y las tecnologías aceptadas por el sector arrocero del Meta en busca de mejores niveles de producción y calidad de sus productos hemos querido desarrollar un sistema que complemente dichos hornos.

AÑO 2006
DISEÑO DE SISTEMA AUTOMATICO ASISTIDO
POR COMPUTADOR PARA EL PROCESO DE EN-
VASADO DE LIQUIDO DE LA PLANTA DE AGUA
PURA SAN SEBASTIÁN 3-0 DE LA CIUDAD DE
VILLAVICENCIO

629.8 G61a

AUTOR

Ronald Fabián Enciso Gallo

RESUMEN

La necesidad de aumentar la productividad y conseguir productos acabados de una manera uniforme está haciendo que cada vez la industria gire hacia una automatización basado en computador.

En este proyecto se describe como se diseña y trabaja un sistema automático asistido por computador para el envasado de líquido de la planta de agua pura SAN SEBASTIAN 3-0 de la ciudad de Villavicencio.

\section{OBJETIVO GENERAL}

Crear un sistema automático asistido por computador para el envasado de líquido de la planta de agua pura SAN SEBASTIAN 3-0 de la ciudad de Villavicencio.

\section{OBJETIVOS ESPECÍFICOS}

-Diseñar la estructura para el almacenamiento y dosificación del líquido.

- Aplicar para el llenado de los recipientes una banda transportadora asistida por motor.

\section{JUSTIFICACIÓN}

Las deficiencias de producción ocasionados por el sistema manual crean la necesidad de diseñar controles automáticos con el fin de aumentar la productividad y conseguir productos acabados de calidad uniforme.

\section{AÑO 2007}

\section{DISEÑO E IMPLEMENTACION DE PROTOTIPO ELECTRÓNICO GUIA PARA INVIDENTES DE RESIDUOS CERRADOS}

\section{$621.381 \mathrm{M} 17 \mathrm{~d}$}

\section{AUTORES}

Yeison Gabriel Marino Vanegas

Jhonatan Alfonso Cardona

\section{RESUMEN}

La necesidad de empresas de informática y de telecomunicaciones de desarrollar una interfaz abierta y de bajo costo para facilitar la comunicación entre dispositivos sin la utilización de cables.

\section{OBJETIVO GENERAL}

Diseñar e implementar un dispositivo electrónico para guiar a personas invidentes dentro de espacios cerrados. 


\section{OBJETIVOS ESPECÍFICOS}

- Diseñar e implementar el protocolo de comunicación que se utilizara en el prototipo.

- Diseñar los módulos TX Y RX del prototipo.

- Realizar el montaje en conjunto del prototipo e implementarlo en el usuario.

\section{JUSTIFICACIÓN}

En nuestro departamento existen poblaciones vulnerables que reciben poco apoyo de parte de los gobiernos que ejercen el poder en nuestros municipios entre estas esta la población de personas con discapacidad visual.

\section{DESARROLLO DE UN ROBOT MOVIL DE CONTROL INTELIGENTE USANDO ALGORITMOS EVOLUTIVOS Y UN FPGA}

\subsection{G 66d}

\section{AUTORES}

Javier Andrés González Hernández

Oscar Mauricio Ayala Guzmán

\section{RESUMEN}

En el presente trabajo de tesis se presentan los aspectos técnicos y teóricos de un sistema inteligente de navegación autónoma basado en el desarrollo de un algoritmo evolutivo.

\section{OBJETIVO GENERAL}

-Desarrollar un robot móvil de navegación autónoma basado en algoritmos evolutivos usando un FPGA.

\section{OBJETIVOS ESPECÍFICOS}

- Diseñar un sistema de automatización y control para el proceso de manufactura de antenas.

- Controlar de manera secuencial todo el proceso de perforación de tubulares.

- Construir un prototipo de máquina que me permita desarrollar la automatización de perforación de tubulares.

\section{JUSTIFICACIÓN}

El aumento de la calidad en los productos se logran mediante la exactitud de las maquinas automatizadas y por la eliminación de los errores propios del ser humano lo que a su vez repercuten en grandes ahorros de tiempo.

\section{ARQUITECTURA}

\section{AÑO 2007}

\section{LA VIVIENDA LLANERA DE SABANA Y SU CONTENIDO SOCIOCULTURAL}

$\mathrm{T} 690.8 / \mathrm{p} 18 \mathrm{v}$

\section{AUTOR}

\author{
Norbert Andrey Patarroyo Hernández

\section{RESUMEN}

Es importante reconocer la vivienda rural tradicional llanera como elemento cultural material presente en los Llanos, ya que cada una de ellas se constituye en un libro abierto que nos relata de forma detallada la vida y costumbres del llanero como individuo y ser social. La vivienda en si misma nos muestra que encaja apropiadamente en contextos como el paisaje, en un sistema de vida productivo como lo son los hatos; bioclimáticamente emplea una tecnología constructiva que responde de manera efectiva frente a la extremidad del clima y conceptualmente su forma, distribución y tamaño se adapta a la vida cotidiana y social del hombre llanero.

\section{OBJETIVO GTENERAL}

Mostrar de manera concreta, cómo la arquitectura doméstica propia de los llanos contiene elementos de carácter, formal, constructivo, climático, entre otros, que son dignos de valorar y que a la vez nos comunican quien es el llanero como individuo y como ser social.

\section{OBJETIVO ESPECIFICO}

- Identificar en el ámbito histórico, cuáles fueron los antecedentesquepudierondarorigenalaviviendaruralllanera. -Entender cómo el clima y el medio geográfico influyen a la hora de concebir una vivienda rural en los llanos. - Describir por medio de los conceptos arquitectónicos, la antropometría y los sistemas constructivos empleados de manera clara y sencilla.

-Identificar los elementos más sobresalientes de carácter ornamental y de su uso cotidiano que identifique la vivienda llanera, así como el espacio y el sistema de manejo de territorio del cual hace parte.

- Explicar la relación que ha habido entre el llanero y su vivienda como medio para entenderlo como individuo, como ser social y su relación con el medio en que se establece. 


\section{JUSTIFICACIÓN}

Es importante reconocer la vivienda rural tradicional llanera como elemento cultural material presente en los llanos, ya que posee componentes de carácter espacial, constructivo, climático y cultural de gran interés que necesitan observaciones y estudio, puesto cada uno de estos constituyen un libro abierto que nos relata de forma detallada la vida y costumbres del llano como individuo y ser social. La vivienda en si misma nos encaja apropiadamente en contextos como el paisaje, en un sistema de vida productivo como lo son los hatos; bioclimáticamente emplea una tecnología constructiva que responde de manera efectiva a la extremidad del clima y conceptualmente su forma, distribución y tamaño se adapta a la vida cotidiana y social del hombre llanero. Culturalmente la vivienda está rodeada de elementos materiales e inmateriales que la destacan como única y distingue frente a otros modelos de vivienda, pudiendo mencionar las celebraciones familiares y religiosas que se realizan en ella como elementos intangibles y la presencia de elementos de uso decorativo y cotidiano que hacen presencia en la vivienda como elementos de carácter material y que la identifican. Todo esto convierte a la vivienda en un símbolo que representa la tradición y la cultura que se mantienen vivos a través del tiempo, y que dentro del proceso de modernización que vive actualmente, es necesario que se mantenga manifiesto como testimonio acerca del arraigo y defensa del folclor y las tradiciones presentes en la cultura llanera.

INGENIERIA CIVIL

\section{AÑO 2005 \\ INVENTARIO Y DIAGNOSTICO DE LOS PUENTES VEHICULARES EN LA CIUDAD DE VILLAVICENCIO}

\section{$624.2 \mathrm{C} 12 \mathrm{i}$}

\section{AUTORES}

Andrea Carolina Cadena Lemus

Diego Alexander Gonzales Valderrama

\section{RESUMEN}

El presente trabajo de grado congrega toda la información del inventario e inspección de puentes en Villavicencio y que se podría aplicar en cualquier parte del departamento y por consiguiente determinar los posibles daños que estos poseen tanto en su superestructura como en su infraestructura.

Para llevar a cabo este proceso se realizó una investigación de la historia de los puentes en Colombia y en el mundo pasado desde los elaborados con troncos de manera hasta los más importantes para la historia del país por su ubicación y gran tamaño.

\section{OBJETIVO GENERAL}

Inventariar y diagnosticar el estado de los puentes vehiculares en la ciudad de Villavicencio.

\section{OBJETIVOS ESPECÍFICOS}

- Determinar el tipo de puentes existentes en la ciudad de Villavicencio.

- Diferenciar las variables que afectan los puentes de la ciudad de Villavicencio.

- Realizar el inventario e inspección de los puentes de la ciudad.

\section{JUSTIFICACIÓN}

Para que la conservación de los puentes sea eficaz, en necesario una serie de procedimientos sistemáticos con el fin de determinar la amplitud de las degradaciones y el nivel de integridad de los puentes, y decidir las medidas correctivas a tomar, es decir, una serie de procesos que van desde el control o examen, al diagnóstico.

\section{IIIIIIIIIIIIIIIIIIIIIIIIIIIIIII}

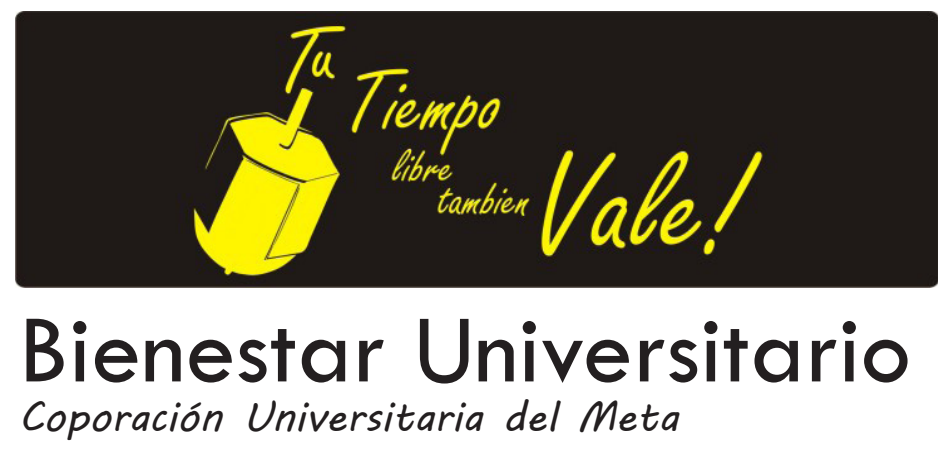

